\title{
Prevention of NSAID-related upper gastrointestinal toxicity: a meta-analysis of traditional NSAIDs with gastroprotection and COX-2 inhibitors
}

This article was published in the following Dove Press journal:

Drug, Healthcare and Patient Safety

27 October 2009

Number of times this article has been viewed

\author{
Alaa Rostom' \\ Katherine Muir ${ }^{2}$ \\ Catherine Dube ${ }^{3}$ \\ Angel Lanas ${ }^{4}$ \\ Emilie Jolicoeur ${ }^{3}$ \\ Peter Tugwell ${ }^{3}$ \\ 'University of Calgary, Calgary, \\ Alberta, Canada; ${ }^{2}$ University \\ of Toronto, Toronto, Ontario, \\ Canada; ${ }^{3}$ University of Ottawa, \\ Ottawa, Ontario, Canada; \\ ${ }^{4}$ University Hospital Lozano \\ Blesa, Instituto Aragones de \\ Ciencias de la Salud, \\ Zaragoza, Spain
}

\begin{abstract}
Background: Traditional NSAIDs (tNSAIDs) and COX-2 inhibitors (COX-2s) are important agents for the treatment of a variety or arthritic conditions. The purpose of this study was to systematically review the effectiveness of misoprostol, H2-receptor antagonists (H2RAs), and proton pump inhibitors (PPIs) for the prevention of tNSAID related upper gastrointestinal (GI) toxicity, and to review the upper gastrointestinal (GI) safety of COX-2s.

Methods: An extensive literature search was performed to identify randomized controlled trials (RCTs) of prophylactic agents used for the prevention of upper GI toxicity, and RCTs that assessed the GI safety of the newer COX-2s. Meta-analysis was performed in accordance with accepted techniques.

Results: 39 gastroprotection and 69 COX-2 RCTs met inclusion criteria. Misoprostol, PPIs, and double doses of H2RAs are effective at reducing the risk of both endoscopic gastric and duodenal tNSAID-induced ulcers. Standard doses of H2RAs are not effective at reducing the risk of tNSAID-induced gastric ulcers, but reduce the risk of duodenal ulcers. Misoprostol is associated with greater adverse effects than the other agents, particularly at higher doses. COX-2s are associated with fewer endoscopic ulcers and clinically important ulcer complications, and have fewer treatment withdrawals due to GI symptoms than tNSAIDS. Acetylsalicylic acid appears to diminish the benefit of COX-2s over tNSAIDs. In high risk GI patients, tNSAID with a PPI or a COX-2 alone appear to offer similar GI safety, but a strategy of a COX-2 with a PPI appears to offer the greatest GI safety.

Conclusion: Several strategies are available to reduce the risk of upper GI toxicity with tNSAIDs. The choice between these strategies needs to consider patients' underlying GI and cardiovascular risk.
\end{abstract}

Keywords: NSAID, gastrointestinal toxicity, COX-2 inhibitors

\section{Introduction}

Nonsteroidal anti-inflammatory drugs (NSAIDs) are widely used to treat arthritis, menstrual, musculoskeletal and post-operative pain, as well as headache and fever. NSAIDs include acetylsalicylic acid (ASA), traditional NSAIDs (tNSAIDs) (eg, diclofenac, ibuprofen, indomethacin, and naproxen) and inhibitors of the COX-2 isoform of cyclo-oxygenase (referred to here as COX-2s, eg, celecoxib, lumiracoxib, etoricoxib, rofecoxib).

One cohort study found that about $25 \%$ of Canadians in 2001 were prescribed short-term NSAIDs (a rise of 28\% over 1999 when COX-2s were first introduced), and about $4 \%$ were prescribed these agents long-term (defined in this study as $\geq 6$ months); ${ }^{1}$ this equates to approximately 6.2 million short-term users, and 1.0 million long-term users of NSAID therapy. However, this substantially underestimates

submit your manuscript $\mid$ www.dovepress.con 
the true magnitude of NSAID uses since it does not include use of over the counter NSAIDs. A US cohort study, reported the point prevalence of daily prescription NSAID use as $8.7 \%$ between 2002 and 2003 with $46 \%$ being COX-2s. ${ }^{2}$ Low-dose ASA is extensively used for cardiovascular risk reduction.

There are increasing concerns over the risks of gastrointestinal and cardiovascular adverse events with these medications. The increased risks of upper gastrointestinal ulcers and complications with tNSAIDs and ASA are well documented, ${ }^{3-7}$ and while the risks are reduced by about $50 \%$ with COX $-2 \mathrm{~s}$, they continue to be important since this risk is not reduced to baseline. ${ }^{8-10}$ Furthermore with the introduction of COX-2s in the late 1990, overall NSAID prescriptions rose with COX-2s overtaking tNSAIDs suggesting that individuals not previously on NSAIDs were being prescribed COX-2s. Over the same time frame, there was a $75.9 \%$ increase in the rate of non-fatal digestive perforations and hemorrhages in the presence of NSAIDs. Moreover, the benefits of COX-2s are attenuated when COX-2s are co-prescribed with $\mathrm{ASA}^{10}$ although to a lesser extent than when tNSAIDs are co-prescribed with ASA. In addition, extensive data associate COX-2s and nonnaproxen tNSAIDs with an increased risk of cardiovascular events, ${ }^{11,12}$ which has led regulatory authorities to introduce warning statements and advisories Additionally, the COX-2s, rofecoxib, valdecoxib, and lumiracoxib have been withdrawn from the market because of cardiovascular, cutaneous, and hepatic adverse events respectively. ${ }^{1,2,13-15}$ Health Canada and the Food and Drug Administration (FDA) require the product information for tNSAIDs and COX-2s to include a warning of the increased incidence of cardiovascular (eg, heart attack, stroke) and gastrointestinal (eg, ulcer, bleeding) adverse events, as well as recommendations to limit use of the drug to the lowest effective dose for the shortest possible duration of treatment. . $^{2,15}$

The purpose of this study was to systematically review the literature on interventions to prevent tNSAID related upper gastrointestinal (GI) toxicity, and on the GI safety of COX-2s.

\section{Methods}

This review was conducted in accordance with the methods of the Cochrane Collaboration. ${ }^{16}$

\section{Literature search strategy}

The search strategy and methods have been previously described elsewhere. These were updated to May 2009. ${ }^{10,17}$

\section{Inclusion criteria}

\section{Types of studies}

RCTs of COX-2s (celecoxib [Celebrex ${ }^{\circledR}$ ], rofecoxib $\left[\right.$ Vioxx $\left.^{\circledR}\right]$, etoricoxib $\left[\right.$ Arcoxia $\left.{ }^{\circledR}\right]$, valdecoxib [Bextra $\left.{ }^{\circledR}\right]$, lumiracoxib [Prexige ${ }^{\circledR}$ ]) were considered eligible for inclusion if the upper GI toxicity of these agents was compared to that of a non-selective NSAID or to placebo. RCTs of prostaglandin analogues (misoprostol), $\mathrm{H}_{2}$-receptor antagonists (H2RA), and proton pump inhibitors (PPI) in the prevention of NSAID-induced upper GI toxicity were also considered if these agents were used alongside an NSAID compared to an NSAID alone. Further the RCTs had to meet the following additional criteria.

Participants were 18 years or older and had osteoarthritis, rheumatoid arthritis or another arthritic condition; NSAID exposure was 4 weeks or longer (chronic NSAID exposure); the proportion of patients with endoscopic ulcers, significant clinical GI events (eg, perforation, obstruction, bleeding, symptomatic ulcers), and/or symptom based clinical events (adverse GI symptoms, withdrawals due to GI symptoms) could be determined; endoscopic ulcers were defined as being at least $3 \mathrm{~mm}$ in diameter or could be distinguished from erosions based on the authors' descriptions; and it was noted whether endoscopy was performed based on symptoms or as part of a protocol.

\section{Types of interventions}

The interventions included the following COX-2s: celecoxib $\left(\right.$ Celebrex $\left.^{\circledR}\right)$, rofecoxib $\left(\operatorname{Vioxx}^{\circledR}\right)$, etoricoxib (Arcoxia $\left.{ }^{\circledR}\right)$, valdecoxib (Bextra ${ }^{\circledR}$ ), lumiracoxib (Prexige ${ }^{\circledR}$ ). For this review, low-dose COX-2s were defined as celecoxib $200 \mathrm{mg}$ bid or less, rofecoxib $25 \mathrm{mg}$ daily or less, etoricoxib $60 \mathrm{mg}$ daily or less, valdecoxib $10 \mathrm{mg}$ daily or less, and lumiracoxib 100 to $200 \mathrm{mg}$. High-dose COX-2s were defined as celecoxib $400 \mathrm{mg}$ bid, rofecoxib $50 \mathrm{mg}$ daily, etoricoxib $90 \mathrm{mg}$ daily or more, valdecoxib $20 \mathrm{mg}$ daily or more, and lumiracoxib $400 \mathrm{mg}$ or more. For prophylaxis against tNSAID induced upper GI toxicity we included: the prostaglandin antagonist misoprostol $\left(\right.$ Cytotec $^{\circledR}$ ) (low dose $400 \mu \mathrm{g} /$ day, intermediate dose $600 \mu \mathrm{g} /$ day; high dose $800 \mu \mathrm{g} /$ day); the PPIs omeprazole, esomeprazole, pantoprazole, and lansoprazole $\left(\right.$ Losec $^{\circledR}$, Nexium $^{\circledR}$, Pantoloc $^{\circledR}$, Prevacid $^{\circledR}$, respectively); and the H2RAs cimetadine, ranitidine, nizatidine, and famotidine (Tagamet $^{\circledR}, Z_{\text {Zantac }}{ }^{\circledR}$, Axid $^{\circledR}$, and Pepcid ${ }^{\circledR}$, respectively). Double doses of H2RAs were defined as a dose equivalent to or greater than $300 \mathrm{mg}$ of ranitidine twice daily, and standard dose of PPIs were considered the equivalent of $20 \mathrm{mg}$ of omeprazole once daily. 


\section{Types of outcome measures}

The primary outcomes were: endoscopically detected ulcer in endoscopy trials; and clinical GI events. Clinically important adverse events were categorized in two ways: 1) strict ulcer complications, which are referred to as "POB" (for perforation, obstruction or bleeding), and 2) ulcer complications and/or ulcer-related symptoms that lead to the identification of an ulcer (so called symptomatic ulcer), which are referred to as "PUB" (for perforation, obstruction, bleeding or the presence of a symptomatic ulcer). Efficacy/tolerability trials were defined as studies that focused on clinical efficacy or effectiveness of COX-2s but also reported on adverse symptoms or other clinical adverse events. Secondary outcomes were: adverse GI symptoms (dyspepsia, nausea, abdominal pain, or diarrhea); and treatment withdrawals due to GI symptoms.

\section{Quality assessment}

All RCTs were scored for quality by 2 independent reviewers using the Jadad scale. ${ }^{18}$ The quality of allocation concealment was also assessed. ${ }^{19}$ Differences were resolved by consensus.

\section{Statistical analysis}

Data were analyzed using Review Manager (RevMan) version 5.0. Endoscopic, clinical and symptom-based outcomes were analyzed separately. The primary analyses were expressed as relative risks using a fixed effects model. A random-effects model was used to combine "heterogeneous trials" only if it was clinically and statistically appropriate. The absolute risk reduction (ARR) was calculated for appropriate clinical endpoints.

\section{Subgroup analyses}

Studies were grouped by interventions (eg, COX-2s vs tNSAIDs, and COX-2s vs placebo), dosage (low-dose and high-dose), and duration of therapy. Additionally, within each of the three main outcome analyses (endoscopic ulcer, clinical ulcer, and symptoms), studies were analyzed as all COX-2s vs all tNSAIDs, individual COX-2s vs all comparator tNSAIDs, individual tNSAIDs vs all comparator COX-2s, and individual COX-2s vs individual tNSAIDs.

\section{Heterogeneity}

Sources for clinical and statistical heterogeneity were sought prior to statistical analyses. Logical analyses subgroups were created (see above) to allow for more homogeneous analyses groups. Heterogeneity was tested using the $\mathrm{I}^{2}$ statistic and a chi-square test. An $\mathrm{I}^{2}>50 \%$ or a chi-square $\mathrm{p}$ value of less than 0.10 is considered to be evidence of statistical heterogeneity. ${ }^{20}$

\section{Sensitivity analyses}

In addition to the published reports, unique studies were identified from the FDA web site, and in the form of published "combined analyses" studies. The latter studies combined published and unpublished primary patient data from the endoscopic studies, as well as the safety and tolerability studies to allow sample sizes large enough to comment on clinical ulcer complications. We carefully examined these studies by their ID number, their sample size, patient demographics and list of authors and cross referenced with the FDA web site in order to ensure that their use in the ulcer complication analyses would not create duplication of individual patient data. Sensitivity analyses were conducted removing or adding FDA studies, and the combined analyses studies. Additionally, sensitivity analyses were used to assess the impact of supplemental FDA data on published study results when available (eg, CLASS study). Sensitivity analysis was also performed removing studies with quality scores of 2 or less.

\section{Results}

\section{Part I - tNSAID prophylaxis}

Of a total of 1205 references with 256 being potentially relevant, 39 RCTs met the inclusion criteria: 23 misoprostol trials (includes 6 head to head studies); 12 H2RA (9 standard dose, 3 double dose, 1 head to head); and 9 PPI trials (6 direct, 5 head to head). Some studies considered more than one active intervention. Table 1 summarizes the characteristics of the included studies. Effects of interventions are summarized below.

\section{Misoprostol}

We found 23 studies that assessed the long term effect of misoprostol on the prevention of tNSAID ulcers. ${ }^{14,21-42}$

\section{Endoscopic ulcers}

Eleven studies with 3,641patients compared the incidence of endoscopic ulcers, after at least 3 months, of misoprostol to that of placebo. ${ }^{21,22,25,29-33,36,38,42}$ The cumulative incidence of endoscopic gastric and duodenal ulcers with placebo were $15 \%$ and $6 \%$ respectively. Misoprostol (any dose combined) significantly reduced the relative risk of gastric ulcer and duodenal ulcers by $74 \%$ relative risk [RR] 0.26 ; $95 \%$ confidence interval [CI] 0.17 to 0.39 , random effects), 
Table I Included studies of gastro-protection

\begin{tabular}{|c|c|c|c|c|c|c|c|}
\hline \multirow[t]{2}{*}{ Study } & \multicolumn{2}{|l|}{ Comparisons } & \multirow[t]{2}{*}{ NSAID } & \multirow[t]{2}{*}{ Number } & \multirow[t]{2}{*}{ Mean age } & \multirow{2}{*}{$\begin{array}{l}\text { Primary or } \\
\text { secondary }\end{array}$} & \multirow{2}{*}{$\begin{array}{l}\text { Follow-up } \\
\text { times } \\
\text { (months) }\end{array}$} \\
\hline & Intervention & Comparator & & & & & \\
\hline \multicolumn{8}{|l|}{ Misoprostol } \\
\hline \multirow[t]{2}{*}{ Graham $^{30}$} & misoprostol $400 \mu \mathrm{g} /$ day & placebo & $\begin{array}{l}\text { ibuprofen, piroxicam, } \\
\text { naproxen }\end{array}$ & 421 & 59 & primary & $1,2,3$ \\
\hline & misoprostol $800 \mu g /$ day & & & & & & \\
\hline Agrawal $^{21}$ & misoprostol $800 \mu g /$ day & placebo & various & 356 & 60 & primary & 3 \\
\hline Chandrasekaran ${ }^{26}$ & misoprostol $600 \mu \mathrm{g} /$ day & placebo & various & 90 & 39 & primary & I \\
\hline Saggioro ${ }^{39}$ & misoprostol $800 \mu g /$ day & placebo & various & 166 & 56 & primary & 1 \\
\hline Bolten ${ }^{24}$ & misoprostol $400-600 \mu \mathrm{g} /$ day & placebo & diclofenac & 361 & 60 & primary & I \\
\hline Verdickt ${ }^{42}$ & misoprostol $400-600 \mu \mathrm{g} /$ day & placebo & diclofenac & 339 & 53 & primary & 3 \\
\hline Melo' 14 & $\begin{array}{l}\text { misoprostol } 400 \mu g / \text { day }+ \\
\text { diclofenac }\end{array}$ & $\begin{array}{l}\text { placebo }+ \\
\text { piroxicam }\end{array}$ & piroxicam & 643 & 60 & primary & I \\
\hline Graham $^{31}$ & misoprostol 800 & placebo & various & 643 & 59 & primary & 3 \\
\hline Henriksson $^{34}$ & misoprostol $600 \mu \mathrm{g} / \mathrm{day}$ & placebo & $\begin{array}{l}\text { naproxen, ibuprofen, } \\
\text { aspirin }\end{array}$ & 40 & 60 & primary & 1 \\
\hline $\operatorname{Roth}^{38}$ & misoprostol 800 & placebo & ibuprofen & 113 & 53 and 60 & primary & 3 \\
\hline Delmas $^{28}$ & $\begin{array}{l}\text { misoprostol } 400 \mu g / d a y \\
\text { misoprostol } 800 \mu g / \text { day }\end{array}$ & placebo & various & 256 & 54 & primary & I \\
\hline Elliott ${ }^{29}$ & misoprostol $600-800 \mu \mathrm{g} /$ day & placebo & various & 83 & 65 & primary & $3,6,12$ \\
\hline Agrawal ${ }^{22}$ & misoprostol $400-600 \mu \mathrm{g} /$ day & placebo & diclofenac & 384 & 57 & secondary & $3,6,12$ \\
\hline Raskin $^{36}$ & $\begin{array}{l}\text { misoprostol } 400 \mu \mathrm{g} / \text { day } \\
\text { misoprostol } 600 \mu \mathrm{g} / \text { day } \\
\text { misoprostol } 800 \mu \mathrm{g} / \text { day }\end{array}$ & placebo & various & 1618 & 58 & primary & 3 \\
\hline Silverstein ${ }^{40}$ & misoprostol $800 \mu \mathrm{g} /$ day & placebo & various & 8843 & 68 & primary & 24 \\
\hline Bocanegra $^{23}$ & $\begin{array}{l}\text { misoprostol } 200 \mu \mathrm{g} \text { bid } \\
\text { misoprostol } 200 \mu \mathrm{g} \text { tid }\end{array}$ & placebo & diclofenac & 481 & 62 & primary & I \\
\hline Chan 25 & misoprostol 200 bid & nabumetone & naproxen & 90 & 74 & secondary & 6 \\
\hline \multicolumn{8}{|l|}{$\mathrm{H} 2$ antagonists } \\
\hline Berkowitz $^{43}$ & ranitidine $150 \mathrm{mg}$ bid & placebo & aspirin & 50 & 28.5 & primary & I \\
\hline Roth $^{140}$ & cimetidine $400 \mathrm{mg} /$ day & placebo & various & 26 & nd & primary & 10 \\
\hline Ehsanullah ${ }^{44}$ & ranitidine $150 \mathrm{mg}$ bid & placebo & various & 297 & 57 & primary & $\mathrm{I}, 2$ \\
\hline Robinson ${ }^{46}$ & ranitidine $150 \mathrm{mg}$ bid & placebo & various & 144 & 48 & primary & $\mathrm{I}, 2$ \\
\hline Swift ${ }^{50}$ & ranitidine $150 \mathrm{mg}$ bid & placebo & various & 24 & 56.5 & primary & 4 \\
\hline Robinson ${ }^{45}$ & ranitidine $150 \mathrm{mg} /$ day & placebo & & 227 & 54.2 & primary & 1 \\
\hline Levine $^{49}$ & nizatidine $150 \mathrm{mg}$ bid & placebo & & 496 & 56.9 & primary & 3 \\
\hline Simon $^{51}$ & nizatidine $150 \mathrm{mg} /$ day & $\begin{array}{l}\text { nizatidine } \\
\text { I50 mg bid }\end{array}$ & & 237 & 58 & secondary & 3,6 \\
\hline \multirow[t]{2}{*}{$\operatorname{Taha}^{47}$} & famotidine $20 \mathrm{mg} /$ day & & & & & primary & I, 3,6 \\
\hline & famotidine $40 \mathrm{mg} /$ day & placebo & various & 285 & 53.4 & & \\
\hline Wolde ${ }^{53}$ & ranitidine 300 bid & placebo & & 30 & $\begin{array}{l}67 \text { ranitidine, } \\
58 \text { placebo }\end{array}$ & secondary & 12 \\
\hline Van Groenendael ${ }^{48}$ & ranitidine I50 mg bid (Grp B) & placebo & various & 36 & 52 & primary & I \\
\hline Hudson ${ }^{52}$ & famotidine $40 \mathrm{mg}$ bid & placebo & various & 78 & 58 & secondary & I, 3,6 \\
\hline
\end{tabular}


Table I (Continued)

\begin{tabular}{|c|c|c|c|c|c|c|c|}
\hline \multirow[t]{2}{*}{ Study } & \multicolumn{2}{|l|}{ Comparisons } & \multirow[t]{2}{*}{ NSAID } & \multirow[t]{2}{*}{ Number } & \multirow[t]{2}{*}{ Mean age } & \multirow{2}{*}{$\begin{array}{l}\text { Primary or } \\
\text { secondary }\end{array}$} & \multirow{2}{*}{$\begin{array}{l}\text { Follow-up } \\
\text { times } \\
\text { (months) }\end{array}$} \\
\hline & Intervention & Comparator & & & & & \\
\hline \multicolumn{8}{|c|}{ Proton pump inhibitors } \\
\hline Cullen ${ }^{55}$ & omeprazole $20 \mathrm{mg} /$ day & placebo & & 168 & & primary & 6 \\
\hline Ekstrom $^{56}$ & omeprazole $20 \mathrm{mg} /$ day & placebo & Various & 177 & 58 & primary & 3 \\
\hline Hawkey ${ }^{85}$ & $\begin{array}{l}\text { misoprostol } 400 \mu g / \text { day } \\
\text { omeprazole } 20 \mathrm{mg} / \text { day }\end{array}$ & placebo & $\begin{array}{l}\text { diclofenac, ketoprofen, } \\
\text { naproxen }\end{array}$ & 725 & 58 & secondary & 6 \\
\hline Bianchi Porro ${ }^{54}$ & pantoprazole 40 mg/day & placebo & various & 104 & 58 & primary & 3 \\
\hline Lai $^{57}$ & lansoprazole $30 \mathrm{mg}$ & placebo & naproxen & 43 & 69 & secondary & 2 \\
\hline \multicolumn{8}{|c|}{ Head to head comparisons } \\
\hline Valentini $^{4 l}$ & $\begin{array}{l}\text { misoprostol } 400 \\
\text { ranitidine } 150 \mathrm{mg} \text { bid }\end{array}$ & & diclofenac & 61 & 59.2 & $44 \%$ & $\mathrm{n} / \mathrm{a}$ \\
\hline Raskin $^{37}$ & misoprostol $800 \mu g /$ day & $\begin{array}{l}\text { ranitidine } \\
150 \mathrm{mg} \text { bid }\end{array}$ & various & 538 & 61 & primary & 2 \\
\hline Hawkey ${ }^{85}$ & $\begin{array}{l}\text { misoprostol } 400 \mu \mathrm{g} / \text { day } \\
\text { omeprazole } 20 \mathrm{mg} / \text { day }\end{array}$ & placebo & $\begin{array}{l}\text { diclofenac, ketoprofen, } \\
\text { naproxen }\end{array}$ & 725 & 58 & secondary & 6 \\
\hline Yeomans $^{58}$ & omeprazole $20 \mathrm{mg} /$ day & $\begin{array}{l}\text { ranitidine } \\
150 \mathrm{mg} \text { bid }\end{array}$ & $\begin{array}{l}\text { diclofenac, } \\
\text { indomethacin, } \\
\text { naproxen }\end{array}$ & 425 & 56 & $30 \%$ & $\mathrm{I}, 2$ \\
\hline Jensen ${ }^{35}$ & misoprostol $200 \mu \mathrm{g}$ qid & $\begin{array}{l}\text { omeprazole } \\
20 \mathrm{mg} \text { bid }\end{array}$ & various & 46 & $\mathrm{n} / \mathrm{a}$ & secondary & 6 \\
\hline Graham $^{32}$ & $\begin{array}{l}\text { misoprostol } 800 \mu g \\
\text { lansoprazole } 15 \mathrm{mg} \\
\text { lansoprazole } 30 \mathrm{mg}\end{array}$ & placebo & various & 537 & 60 & secondary & 3 \\
\hline Stupnicki ${ }^{13}$ & misoprostol $400 \mu \mathrm{g} /$ day & $\begin{array}{l}\text { pantoprazole } \\
40 \mathrm{mg} / \text { day }\end{array}$ & diclofenac & 515 & 55 & primary & 1 \\
\hline
\end{tabular}

and $58 \%$ (RR $0.42 ; 95 \%$ CI 0.22 to 0.81 , random effects). These relative risks correspond to a $12.0 \%$, and $3 \%$ absolute risk reductions for gastric and duodenal ulcers respectively. The observed heterogeneity in these estimates was due to inclusion of all misoprostol doses in the analyses. Analysis of the misoprostol studies stratified by dose eliminated this heterogeneity.

\section{Analysis by dose}

All the studied doses of misoprostol significantly reduced the risk of endoscopic ulcers, and a dose response relationship was demonstrated for endoscopic gastric ulcers. Six studies with 2,461 patients used misoprostol $400 \mu \mathrm{g}$. 22,25,30,33,36,42 1 study with 928 patients used $600 \mu \mathrm{g}$ daily, ${ }^{36}$ and 7 with 2,423 patients used $800 \mu \mathrm{g}$ daily. ${ }^{21,29-32,36,38}$ Misoprostol $800 \mu \mathrm{g}$ daily was associated with the lowest risk (RR 0.17; 95\% CI 0.11 to 0.24 ) of endoscopic gastric ulcers when compared to placebo, whereas misoprostol $400 \mathrm{ug}$ daily was associated with a relative risk of 0.42 (95\% CI 0.28 to 0.67 , random effects model for heterogeneity) (Figure 1).
This difference between high- and low-dose misoprostol reached statistical significance $(P 0.0055)$. The intermediate misoprostol dose $(600 \mu \mathrm{g}$ daily) was not statistically different from either the low or high dose. The pooled relative risk reduction of $78 \%$ (4.7\% absolute risk difference, RR 0.21 ; $95 \%$ CI 0.09 to 0.49 ) for duodenal ulcers with misoprostol $800 \mu \mathrm{g}$ daily was not statistically different from those of the lower daily misoprostol dosages.

\section{Studies including data with less than 3 months tNSAID exposure}

Eight studies, with 2,206 patients, assessed the rates of endoscopic ulcers with misoprostol compared to placebo at 1 to 1.5 months. ${ }^{14,23,24,26,28,29,34,39}$ The pooling of these studies revealed an $81 \%$ relative risk reduction of gastric ulcers with misoprostol (RR 0.17; 95\% CI 0.09 to 0.31 ) and an $72 \%$ relative risk reduction of duodenal ulcers (RR 0.28 ; $95 \%$ CI 0.14 to 0.56 ).

One study compared misoprostol to a newer cytoprotective agent, dosmafate, for tNSAID prophylaxis and found no 


\begin{tabular}{|c|c|c|c|c|c|c|c|c|}
\hline Study or Subgroup & \multicolumn{2}{|c|}{ Misoprostol } & $\begin{array}{l}\text { Contr } \\
\text { Events }\end{array}$ & $\begin{array}{l}\text { rol } \\
\text { Total }\end{array}$ & Weight & $\begin{array}{c}\text { Risk Ratio } \\
\text { M-H, Fixed, 95\% Cl }\end{array}$ & \multicolumn{2}{|c|}{$\begin{array}{c}\text { Risk Ratio } \\
\text { M-H, Fixed, 95\% Cl }\end{array}$} \\
\hline \multicolumn{9}{|c|}{ 4.4.1 Low dose $(400-600 \mu \mathrm{g})$} \\
\hline Agrawal $^{22}$ & 6 & 193 & 20 & 191 & $11.5 \%$ & $0.30[0.12,0.72]$ & & \\
\hline $\mathrm{Chan}^{25}$ & 5 & 45 & 2 & 45 & $1.1 \%$ & $2.50[0.51,12.22]$ & & \\
\hline Graham $^{30}$ & 8 & 143 & 30 & 138 & $17.4 \%$ & $0.26[0.12,0.54]$ & & \\
\hline Hawkey ${ }^{33}$ & 31 & 296 & 50 & 155 & $37.4 \%$ & $0.32[0.22,0.49]$ & - & \\
\hline Raskin ${ }^{36}$ & 29 & 462 & 51 & 454 & $29.3 \%$ & $0.56[0.36,0.87]$ & - & \\
\hline $\begin{array}{l}\text { Verdickt }{ }^{42} \\
\text { Subtotal }(95 \% \mathrm{Cl})\end{array}$ & 4 & $\begin{array}{r}164 \\
1303\end{array}$ & 6 & $\begin{array}{r}175 \\
1158\end{array}$ & $\begin{array}{r}3.3 \% \\
100.0 \%\end{array}$ & $\begin{array}{l}0.71[0.20,2.48] \\
\mathbf{0 . 4 2}[\mathbf{0 . 3 2}, \mathbf{0 . 5 3}]\end{array}$ & & \\
\hline $\begin{array}{l}\text { Total events } \\
\text { Heterogeneity: } \mathrm{Chi}^{2}= \\
\text { Test for overall effect: }\end{array}$ & $\begin{array}{r}83 \\
0.97, \mathrm{df}= \\
=6.88(F\end{array}$ & $\begin{array}{l}5(P=C \\
<0.00\end{array}$ & $\begin{array}{l}159 \\
.05) ;\left.\right|^{2}= \\
01)\end{array}$ & $54 \%$ & & & & \\
\hline \multicolumn{9}{|c|}{ 4.4.2 Mid-range dose $(600 \mu \mathrm{g})$} \\
\hline $\begin{array}{l}\text { Raskin }^{36} \\
\text { Subtotal }(95 \% \mathrm{Cl})\end{array}$ & 13 & $\begin{array}{l}474 \\
474\end{array}$ & 51 & $\begin{array}{l}454 \\
454\end{array}$ & $\begin{array}{l}100.0 \% \\
100.0 \%\end{array}$ & $\begin{array}{l}0.24[0.13,0.44] \\
0.24[0.13,0.44]\end{array}$ & & \\
\hline \multicolumn{9}{|c|}{$\begin{array}{l}\text { Heterogeneity: Not applicable } \\
\text { Test for overall effect: } Z=4.64(P<0.00001)\end{array}$} \\
\hline \multicolumn{9}{|c|}{ 4.4.3 High dose $(800 \mu \mathrm{g})$} \\
\hline Agrawal $^{21}$ & 2 & 179 & 21 & 177 & $11.5 \%$ & $0.09[0.02,0.40]$ & & \\
\hline Elliott ${ }^{29}$ & 4 & 40 & 11 & 43 & $5.8 \%$ & $0.39[0.14,1.13]$ & & \\
\hline Graham $^{30}$ & 2 & 140 & 30 & 138 & $16.5 \%$ & $0.07[0.02,0.27]$ & $\longleftarrow$ & \\
\hline Graham $^{31}$ & 6 & 320 & 25 & 323 & $13.6 \%$ & $0.24[0.10,0.58]$ & & \\
\hline Graham $^{32}$ & 8 & 111 & 54 & 111 & $29.5 \%$ & $0.15[0.07,0.30]$ & & \\
\hline Raskin ${ }^{36}$ & 6 & 228 & 51 & 454 & $18.6 \%$ & $0.23[0.10,0.54]$ & & \\
\hline $\begin{array}{l}\text { Roth }^{38} \\
\text { Subtotal }(95 \% \mathrm{Cl})\end{array}$ & 0 & $\begin{array}{r}60 \\
1078\end{array}$ & 7 & $\begin{array}{r}53 \\
1299\end{array}$ & $\begin{array}{r}4.4 \% \\
100.0 \%\end{array}$ & $\begin{array}{l}0.06[0.00,1.01] \\
\mathbf{0 . 1 7}[\mathbf{0 . 1 1}, \mathbf{0 . 2 4}]\end{array}$ & & \\
\hline \multicolumn{9}{|c|}{$\begin{array}{l}\text { Heterogeneity: } \text { Chi }^{2}=6.71, \mathrm{df}=6(P=0.35) ; I^{2}=11 \% \\
\text { Test for overall effect: } Z=9.28(P<0.00001)\end{array}$} \\
\hline & & & & & & & $\begin{array}{lc}+1 \\
0.02 & 0.1 \\
\text { avors misoprostol }\end{array}$ & $\begin{array}{lcc} & 1 & + \\
1 & 10 & 50\end{array}$ \\
\hline
\end{tabular}

Figure I Misoprostol vs placebo for the prevention of gastric ulcers - efficacy by dose.

statistically significant difference in ulcer rates between the two agents. ${ }^{27}$

\section{Clinical ulcers}

Only 1 RCT, the MUCOSA trial, evaluated the efficacy of misoprostol prophylaxis against clinically important TNSAID induced ulcer complications as the powered primary endpoint. In this study, of 8,843 patients studied over 6 months, the overall GI event incidence was about 1.5\% per year. ${ }^{40}$ Misoprostol $800 \mu \mathrm{g} /$ day was associated with a statistically significant $40 \%$ risk reduction (odds ratio $0.598 ; 95 \% \mathrm{CI}$ 0.364 to 0.982$)$ in combined GI events $(P 0.049)$, representing a risk difference of $0.38 \%$ (from $0.95 \%$ to $0.57 \%$ ).

\section{Adverse effects}

Misoprostol was associated with a small but statistically significant 1.6 fold excess risk of drop out due to drug induced side effects, and an excess risk of drop-outs due to nausea (RR 1.30; 95\% CI 1.08 to 1.55), diarrhea (RR 2.36; 95\% CI 2.01 to 2.77 ), and abdominal pain (RR 1.36; 95\% CI 1.20 to 1.55$)$. In the MUCOSA trial, 732 out of 4,404 patients on misoprostol experienced diarrhea or abdominal pain, compared to 399 out of 4,439 on placebo for a relative risk of 1.82 associated with misoprostol $(P<0.001)$. Overall $27 \%$ of patients on misoprostol experienced one or more side effects. ${ }^{40}$

When analyzed by dose, only misoprostol $800 \mu \mathrm{g}$ daily showed a statistically significant excess risk of drop-outs due to diarrhea (RR 2.45; 95\% CI 2.09 to 2.88), and abdominal pain (RR 1.38; 95\% CI 1.17 to 1.63 ). Both misoprostol doses were associated with a statistically significant risk of diarrhea. However, the risk of diarrhea with $800 \mu \mathrm{g}$ /day (RR 3.25; 95\% CI 2.60 to 4.06 ) was significantly higher than that seen with 
$400 \mu \mathrm{g} /$ day (RR $1.8195 \%$ CI 1.52 to 2.16 ) (P0.0012). The results for overall dropouts due to symptoms analyzed by dose are shown in Figure 2.

\section{H2RAs}

Seven trials with over 900 patients assessed the effect of standard dose H2RAs on the prevention of endoscopic tNSAID ulcers at 1 month, ${ }^{43-48}$ and 5 trials with 1,005 patients assessed these outcomes at 3 months or longer. ${ }^{44,47,49-51}$ Standard dose $\mathrm{H} 2 \mathrm{RAs}$ are effective at reducing the risk of duodenal ulcers (RR $0.24 ; 95 \%$ CI 0.10 to 0.57 , and RR $0.36 ; 95 \%$ CI 0.18 to 0.74 at 1 and 3 or more months respectively), but not of gastric ulcers (NS). One study did not have a placebo comparator and was not included in the pooled estimate..$^{51}$
Three RCTs with 298 patients assessed the efficacy of double dose H2RA for the prevention of tNSAID induced upper GI toxicity. ${ }^{47,52,53}$ Double-dose H2RAs when compared to placebo were associated with a statistically significant reduction in the risk of both duodenal (RR 0.26; 95\% CI 0.11 to 0.65 ) and gastric ulcers (RR $0.44 ; 95 \%$ CI 026 to 0.74 ). This $56 \%$ relative risk reduction in gastric ulcer corresponds to a $12 \%$ absolute risk difference (from $23.1 \%$ to $11.3 \%$ ) (Figures 3 and 4). Analysis of the secondary prophylaxis studies alone yielded similar results.

\section{Symptoms}

H2RA, in standard or double doses, were not associated with an excess risk of total drop-outs, dropouts due to side effects,
Treatment

Study or Subgroup Events Total Events Total Weigh 5.8.1 Misoprostol $400 \mu \mathrm{g} /$ day

\begin{tabular}{lrrrrr} 
Agrawal $^{22}$ & 11 & 193 & 9 & 191 & $10.3 \%$ \\
Bolten $^{24}$ & 11 & 178 & 10 & 183 & $11.2 \%$ \\
Delmas $^{28}$ & 5 & 73 & 6 & 103 & $5.7 \%$ \\
Raskin $^{36}$ & 55 & 462 & 49 & 454 & $56.3 \%$ \\
Verdickt $^{42}$ & 18 & 164 & 15 & 175 & $16.5 \%$ \\
Subtotal (95\% CI) & & $\mathbf{1 0 7 0}$ & & $\mathbf{1 1 0 6}$ & $\mathbf{1 0 0 . 0 \%}$ \\
Total events & 100 & \multicolumn{5}{c}{89}
\end{tabular}

Heterogeneity: $\mathrm{Chi}^{2}=0.17, \mathrm{df}=4(P=1.00) ; \mathrm{I}^{2}=0 \%$

Test for overall effect: $Z=1.01(P=0.31)$

\subsubsection{Misoprostol $600 \mu \mathrm{g} / \mathrm{day}$}

\begin{tabular}{|c|c|c|c|c|c|}
\hline $\begin{array}{l}\text { Raskin }^{36} \\
\text { Subtotal }(\mathbf{9 5 \%} \mathrm{Cl})\end{array}$ & 56 & $\begin{array}{l}474 \\
474\end{array}$ & 49 & $\begin{array}{l}454 \\
454\end{array}$ & $\begin{array}{l}100.0 \% \\
100.0 \%\end{array}$ \\
\hline Total events & 56 & & 49 & & \\
\hline \multicolumn{6}{|c|}{ Heterogeneity: Not applicable } \\
\hline \multicolumn{6}{|c|}{ Test for overall effect: $Z=0.49(P=0.62)$} \\
\hline \multicolumn{6}{|c|}{ 5.8.3 Misoprostol $800 \mu \mathrm{g} /$ day } \\
\hline Agrawal $^{21}$ & 31 & 179 & 16 & 177 & $1.6 \%$ \\
\hline Delmas $^{28}$ & 10 & 80 & 6 & 103 & $0.5 \%$ \\
\hline Elliott ${ }^{29}$ & 5 & 40 & 1 & 43 & $0.1 \%$ \\
\hline Graham $^{31}$ & 38 & 320 & 34 & 323 & $3.4 \%$ \\
\hline Hawkey ${ }^{33}$ & 23 & 297 & 3 & 155 & $0.4 \%$ \\
\hline Raskin ${ }^{36}$ & 46 & 228 & 49 & 454 & $3.3 \%$ \\
\hline Roth $^{38}$ & 9 & 60 & 2 & 53 & $0.2 \%$ \\
\hline Saggioro ${ }^{39}$ & 6 & 82 & 1 & 84 & $0.1 \%$ \\
\hline Silverstein ${ }^{40}$ & 1210 & 4404 & 896 & 4439 & $90.3 \%$ \\
\hline Subtotal $(95 \% \mathrm{Cl})$ & & 5690 & & 5831 & $100.0 \%$ \\
\hline Total events & 1378 & & 1008 & & \\
\hline
\end{tabular}

Heterogeneity: $\mathrm{Chi}^{2}=14.18, \mathrm{df}=8(P=0.08) ; \mathrm{I}^{2}=44 \%$

Test for overall effect: $Z=9.33(P<0.00001)$
Risk Ratio

M-H, Fixed, 95\% Cl

$1.21[0.51,2.85]$

$1.13[0.49,2.60]$

$1.18[0.37,3.71]$

$1.10[0.77,1.59]$

$1.28[0.67,2.46]$

$1.15[0.88,1.51]$

$1.09[0.76,1.57]$

$1.09[0.76,1.57]$

$1.92[1.09,3.38]$

$2.15[0.81,5.66]$

$5.38[0.66,44.04]$

$1.13[0.73,1.74]$

$4.00[1.22,13.12]$

$1.87[1.29,2.71]$

$3.98[0.90,17.58]$

$6.15[0.76,49.94]$

$1.36[1.26,1.47]$

$1.41[1.31,1.51]$
Risk Ratio M-H, Fixed, 95\% CI

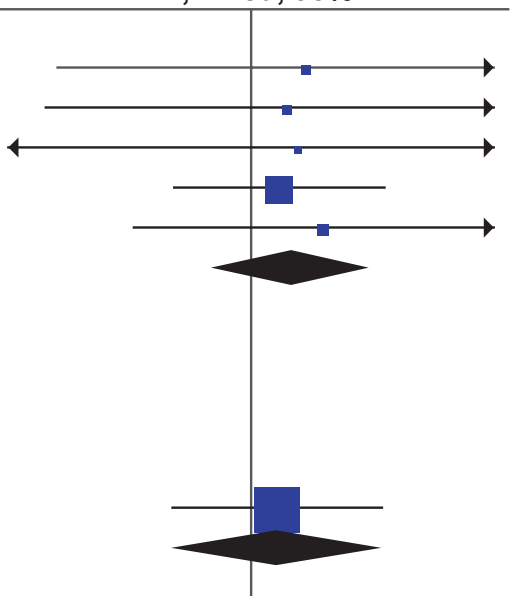




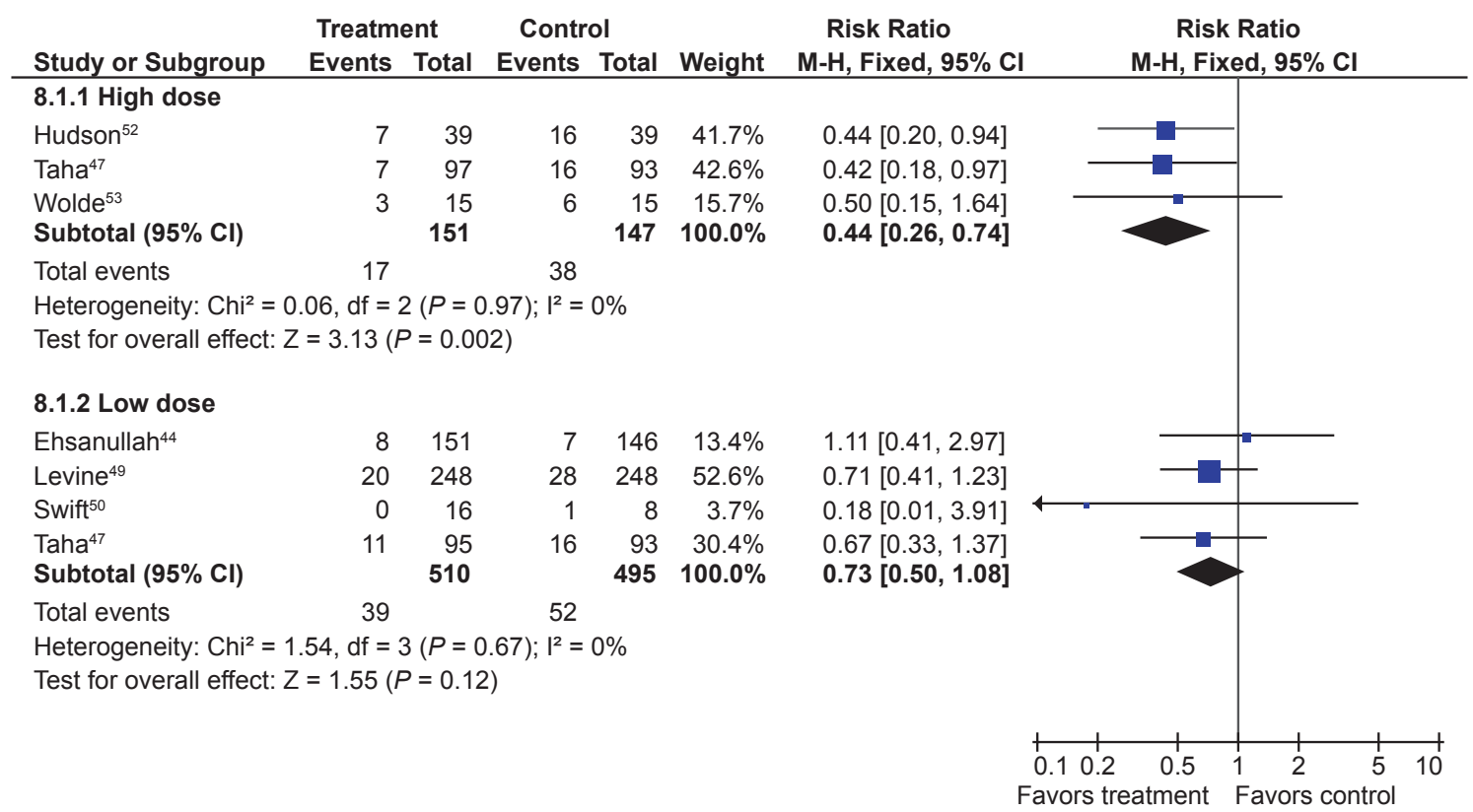

Figure 3 H2RAs compared to placebo for the prevention of gastric ulcer. Analysis by dose in studies of 12 weeks or longer duration.

or symptoms compared to placebo. However, high-dose H2RAs significantly reduced symptoms of abdominal pain when compared to placebo (RR $0.57,95 \%$ CI 0.33 to 0.98 ).

\section{PPIs}

Six RCTs with 1,259 patients assessed the effect of PPIs on the prevention of NSAID-induced upper GI toxicity. ${ }^{32,33,54-57}$

PPIs significantly reduced the risk of both endoscopic duodenal (RR 0.20; $95 \%$ CI 0.10 to 0.39 ) and gastric ulcers
(RR $0.39 ; 95 \%$ CI 0.31 to 0.50 ) compared to placebo (Figures 5 and 6)..$^{32,33,54-57}$ The results were similar for both primary and secondary prophylaxis trials.

\section{Symptoms}

Four omeprazole trials used the same composite endpoints to define treatment success. ${ }^{33,55,56,58}$ In these trials omeprazole significantly reduced "dyspeptic symptoms" as defined by the authors. In the combined analysis, drop-outs overall

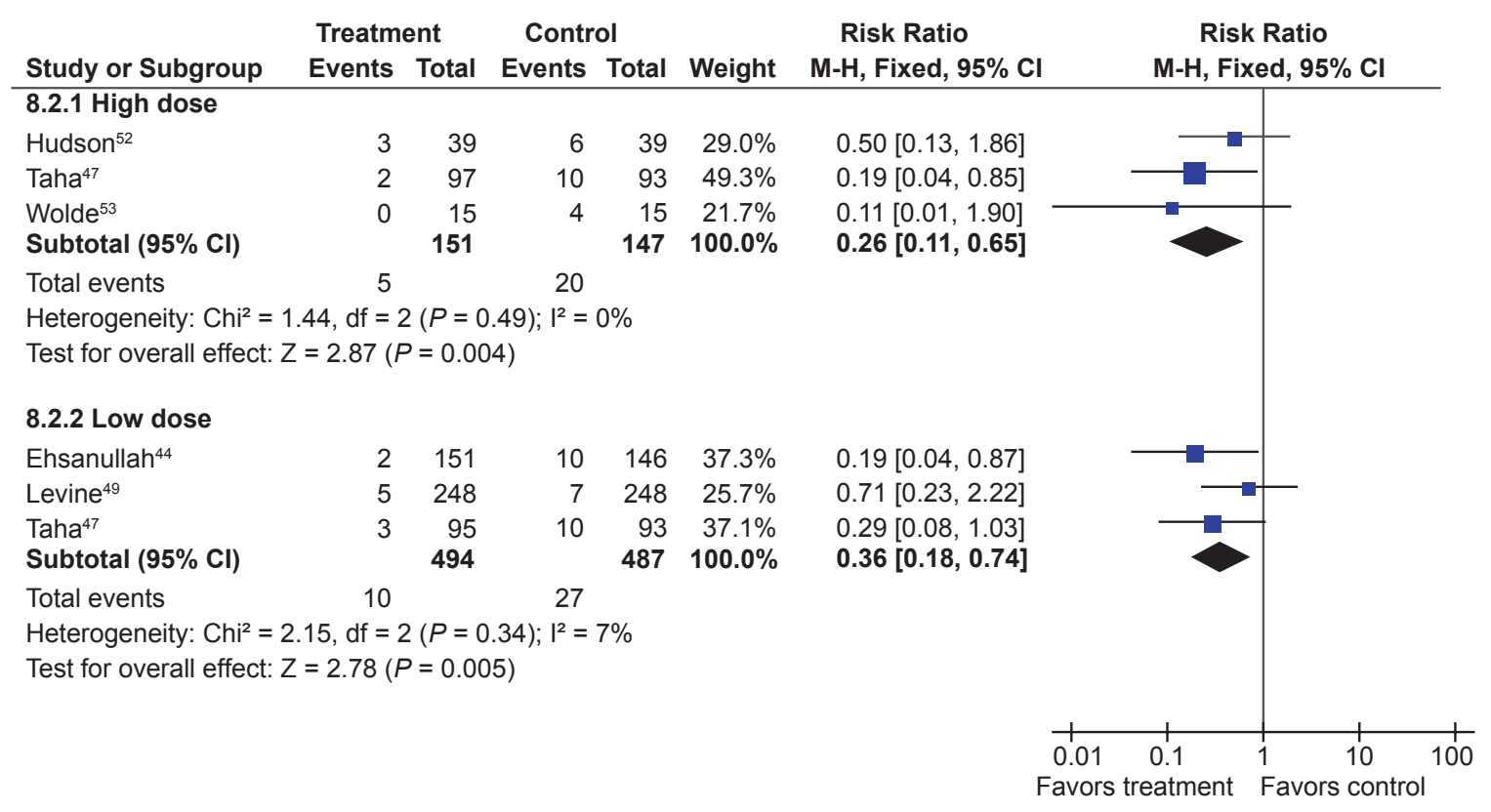

Figure 4 H2RAs compared to placebo for the prevention of duodenal ulcer. Analysis by dose in studies of 12 weeks or longer duration. 


\begin{tabular}{|c|c|c|c|c|c|c|c|c|}
\hline Study or Subgroup & \multicolumn{2}{|c|}{ Treatment } & \multicolumn{2}{|c|}{ Control } & Weight & $\begin{array}{c}\text { Risk Ratio } \\
\text { M-H, Fixed, } 95 \% \mathrm{Cl}\end{array}$ & \multicolumn{2}{|c|}{$\begin{array}{c}\text { Risk Ratio } \\
\text { M-H, Fixed, 95\% Cl }\end{array}$} \\
\hline Bianchi Porro 54 & 7 & 43 & 5 & 23 & $3.9 \%$ & $0.75[0.27,2.10]$ & & \\
\hline Cullen ${ }^{55}$ & 3 & 83 & 9 & 85 & $5.4 \%$ & $0.34[0.10,1.22]$ & & \\
\hline Ekstrom $^{56}$ & 2 & 86 & 6 & 91 & $3.5 \%$ & $0.35[0.07,1.70]$ & 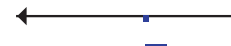 & \\
\hline Graham $^{32}$ & 45 & 236 & 54 & 111 & $44.3 \%$ & $0.39[0.28,0.54]$ & & \\
\hline Hawkey ${ }^{33}$ & 35 & 274 & 50 & 155 & $38.5 \%$ & $0.40[0.27,0.58]$ & & \\
\hline $\mathrm{Lai}^{57}$ & 1 & 22 & 7 & 21 & $4.3 \%$ & $0.14[0.02,1.02]$ & 4 & \\
\hline Total $(95 \% \mathrm{Cl})$ & & 744 & & 486 & $100.0 \%$ & $0.39[0.31,0.50]$ & & \\
\hline Total events & 93 & & 131 & & & & & \\
\hline $\begin{array}{l}\text { Heterogeneity: } \mathrm{Chi}^{2}= \\
\text { Test for overall effect: }\end{array}$ & $\begin{array}{l}.64, \mathrm{df}=5 \\
=7.79(P\end{array}$ & $\begin{array}{l}5(P=c \\
D<0.06\end{array}$ & $\begin{array}{l}.75) ; 1^{2}= \\
001)\end{array}$ & & & & $\begin{array}{ccc} & 1 & 1 \\
0.1 & 0.2 & 0.5 \\
\text { Favors treatment }\end{array}$ & $\begin{array}{lccc}1 & 1 & 1 & 1 \\
1 & 2 & 5 & 10 \\
\text { Favors control } & \end{array}$ \\
\hline
\end{tabular}

Figure 5 Proton pump inhibitors compared to placebo for the prevention of gastric ulcer in studies of 8 weeks or longer duration.

(RR $0.89 ; 95 \%$ CI 0.62 to 1.29 ) and drop-outs due to side effects (RR 1.20; 95\% CI 0.66 to 2.15 ) were not different from placebo.

\section{Head to head comparisons of gastroprotective agents} Misoprostol vs H2RAs

Two trials with 600 patients compared misoprostol (400 to $800 \mu \mathrm{g}$ ) to ranitidine $150 \mathrm{mg}$ twice daily. ${ }^{36,41}$ Misoprostol appears superior to standard dose ranitidine for the prevention of tNSAID induced gastric ulcers (RR 0.12;95\% CI 0.03 to 0.51 ) but not for duodenal ulcers (RR $1.00 ; 95 \% \mathrm{CI}$ 0.14 to 7.14$)$.

\section{PPI vs H2RAS}

Yeomans et al in a 12 -week study of 425 patients, compared omeprazole $20 \mathrm{mg}$ daily to ranitidine $150 \mathrm{mg}$ twice daily for tNSAID prophylaxis (various tNSAIDs used). ${ }^{58}$ In this study, omeprazole was superior to standard-dose ranitidine for the prevention of both gastric (RR $0.32 ; 95 \%$ CI 0.17 to 0.62 ) and duodenal ulcers (RR $0.11 ; 95 \%$ CI 0.01 to 0.89 ).

\section{PPI vs misoprostol}

Four trials with a total of 1,478 patients $^{13,32,33,35}$ compared a PPI to misoprostol. Two studies compared low-dose misoprostol $(400 \mu \mathrm{g})$ daily to a standard-dose PPI ${ }^{13,33}$ while the Graham study compared high-dose misoprostol $(800 \mu \mathrm{g})$ to lansoprazole 15 or $30 \mathrm{mg}$ daily. PPIs are superior to misoprostol for the prevention of duodenal (RR 0.25 ; $95 \%$ CI 0.11 to 0.056 ), but not gastric (RR 1.61; 95\% CI 0.88 to 3.06 , random effects) or total gastroduodenal ulcers (RR $0.90 ; 95 \%$ CI 0.47 to 1.72 , random effects).

\section{Symptoms}

In the two head to head comparison of omeprazole and misoprostol, ${ }^{32,33}$ PPIs were associated with significantly less drop-outs overall (RR 0.71 ; 95\% CI 0.52 to 0.97 ), as well as significantly less drop-outs due to side effects (RR 0.48; $09 \%$ CI 0.29 to 0.78 ). Compared to H2RA used for less than 2 months, misoprostol caused significantly more drop-outs due to abdominal pain (RR 3.00, 95\% CI 1.11 to 8.14 ) and more symptoms of diarrhea (RR 2.03, 95\% CI 1.38 to 2.99 ). There were no significant differences in drop-outs due to

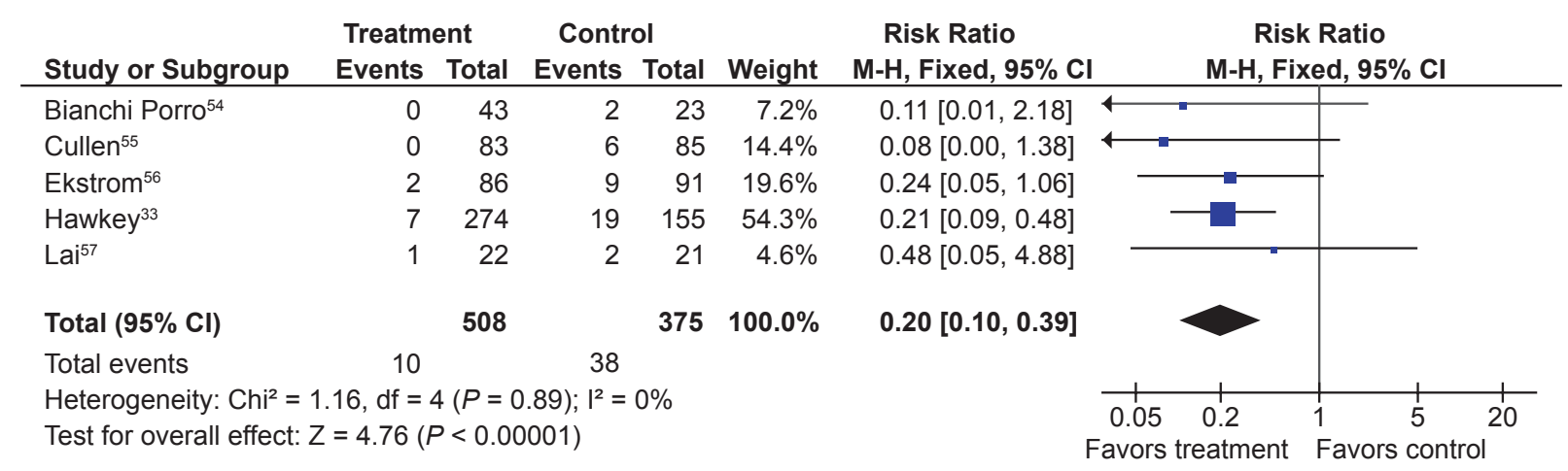

Figure 6 Proton pump inhibitors compared to placebo for the prevention of duodenal ulcer in studies of 8 weeks or longer duration. 
side effects (RR 1.90, 95\% CI 0.77 to 4.67 ) or symptoms of abdominal pain or diarrhea between low-dose H2RAs and PPIs.

\section{Part II - COX-2 inhibitors}

The search strategy identified 1,169 studies. Of these, 255 references were rated as potentially relevant and the full articles were retrieved. Sixty studies met the inclusion criteria, including 4 unique studies obtained from the new drug submission documents on the FDA web site. ${ }^{59-63}$ An additional 5 "combined analyses studies" were identified by the search strategy and were included for the clinical ulcer complication endpoint (Table 2). ${ }^{64-68}$

Quality scores of the 60 included trials ranged between 4 to 5 in 47 and between 2 to 3 in 22 studies. Removal of quality score 2 studies did not influence overall results. The use of allocation concealment was implied in all of the included trials, but was adequately described in only 6 studies.

Endoscopic ulcers were the measured endpoints of 17 studies. . $9-61,63,69-81$ Eleven COX-2 studies, ${ }^{78,82-91}$ and 5 combined analyses ${ }^{65-68,92}$ reported on the outcome of clinical GI events (POBs or PUBs).

The remaining trials were either safety or tolerability studies or examined the clinical efficacy of COX-2s compared to tNSAIDS, but allowed for extraction of GI tolerability data. ${ }^{62,67,88,93-111}$ FDA study data are only presented as part of sensitivity analyses. Results specifically pertaining to meloxicam are not included herein.

\section{Endoscopic ulcer trials}

\section{CoX-2s vs non-selective NSAIDs}

Seventeen studies with over 10,000 patients assessed the proportion of patients who developed endoscopic ulcers while taking a COX-2 compared to those taking a tNSAID. ${ }^{59-61,63,69-79,81}$ Seven studies assessed celecoxib, ${ }^{59,60,69-71,75,81} 3$ assessed rofecoxib, ${ }^{72-74} 2$ assessed etoricoxib, ${ }^{78,79} 5$ that assessed valdecoxib, ${ }^{61,63,76,77,80}$ and 2 assessed lumiracoxib. ${ }^{75,81}$ Some studies assessed more than one intervention. ${ }^{75,81}$

\section{Endoscopically detected gastro-duodenal ulcers}

Thirteen studies with a total of 7,839 patients showed a 74\% relative risk reduction (RRR ) in combined gastro-duodenal ulcers with COX-2s vs tNSAIDs (RR 0.26; 95\% CI 0.23 to 0.30). ${ }^{69-80,112}$ This represented a $16 \%$ absolute risk reduction (ARR). Addition of the FDA studies did not significantly alter the results (RR $0.28 ; 95 \%$ CI 0.24 to 0.32 ). The results analyzed by the dose of COX-2s gave similar results. Results below are for "any dose" combined.
Eleven studies with a total of 6,726 patients compared the safety of a COX-2 to a comparator tNSAID for endoscopic gastric ulcers. ${ }^{69-77,80,112}$ The use of a COX-2 in this setting was associated with a 79\% RRR in gastric ulcers (RR 0.21; 95\% CI 0.18 to 0.25 ) (Figure 7). This represented a $14 \%$ ARR in gastric ulcers with the use of COX-2s compared with tNSAIDs. Addition of the FDA studies did not significantly alter the results (RR 0.26 ; 95\% CI 0.22 to 0.30 ).

The same 11 studies also compared the proportions of duodenal ulcers that occurred while using a COX-2 vs a tNSAID. ${ }^{69-77,80,112}$ Compared to using a tNSAID, the use of a COX-2 was associated with a $66 \%$ RRR in duodenal ulcers (RR 0.34; 95\% CI 0.25 to 0.45) (Figure 7). This represented a $3 \%$ ARR. Addition of the FDA studies did not significantly alter the results (RR 0.29 ; 95\% CI 0.23 to 0.38$)$ Keeping in mind that tNSAID related gastric ulcers were more commonly observed than duodenal ulcer, a trend was observed for greater RRR and ARR in gastric ulcers than for duodenal ulcers with COX-2s, compared to tNSAIDs (RR 0.21 vs 0.34 , ARR of $14 \%$ vs $3 \%$ ). This trend was consistent when celecoxib, rofecoxib and valdecoxib were analyzed separately. Analysis by duration The data presented above are for any dose and duration up to 6 months. Subgroup analysis of these studies on the basis of duration (1 to 3 months and 3 to 6 months) did not significantly alter the results.

\section{Analysis by COX-2}

Analyses stratified by the individual COX-2s showed that each of the studied agents were safer than comparator tNSAIDs (Figure 8).

\section{Celecoxib}

Five studies with a total of 2,439 patients compared celecoxib to non-selective NSAIDs, showing a 79\% RRR in total gastro-duodenal ulcers (RR 0.21 ; 95\% CI 0.16 to 0.28 ) with celecoxib. ${ }^{69-71,75,112}$ Similar RRR were observed for gastric ulcers (RR $0.20 ; 95 \%$ CI 0.14 to 0.28 ) and duodenal ulcers alone (RR 0.29 ; 95\% CI 0.18 to 0.47 ), as well as when the FDA studies were included (RR 0.26; 95\% CI 0.21 to 0.32 ).

\section{Rofecoxib}

Three studies with a total of 1,526 patients compared rofecoxib to non-selective NSAIDs. ${ }^{72-74}$ In this case, a 74\% RRR was seen with rofecoxib (RR 0.26 ; 95\% CI: 0.21 to 0.32 ). The results were similar when FDA studies were added to the analysis as well as when the analysis was done only for gastric ulcers (RR 0.20; 95\% CI 0.15 to 0.26 ) and duodenal ulcers alone (RR 0.36; 95\% CI 0.14 to 0.93 , random effects). 
Table 2 COX-2 included studies

\begin{tabular}{|c|c|c|c|c|c|c|c|}
\hline \multirow[t]{2}{*}{ Endpoint } & \multirow[t]{2}{*}{ Study } & \multicolumn{2}{|l|}{ Comparisons } & \multirow{2}{*}{$\begin{array}{l}\text { Number } \\
\text { of patients }\end{array}$} & \multirow{2}{*}{$\begin{array}{l}\text { Mean } \\
\text { age }\end{array}$} & \multirow{2}{*}{$\begin{array}{l}\text { Arthritis } \\
\text { type }\end{array}$} & \multirow[t]{2}{*}{ Follow-up } \\
\hline & & Intervention & Comparator & & & & \\
\hline \multirow{21}{*}{$\begin{array}{l}\text { Endoscopic } \\
\text { ulcer }\end{array}$} & Celecoxib & & & & & & \\
\hline & Emery $^{70}$ & $200 \mathrm{mg}$ bid & diclofenac $75 \mathrm{mg}$ bid & 655 & 55 & RA & 24 weeks \\
\hline & FDA, 021 & $\begin{array}{l}50 \mathrm{mg} \text { bid, } 100 \mathrm{mg} \text { bid, } \\
200 \mathrm{mg} \text { bid }\end{array}$ & $\begin{array}{l}\text { naproxen } 500 \text { mg bid; } \\
\text { placebo }\end{array}$ & $\mathrm{I}, 108$ & unk & OA & $2,6,12$ weeks \\
\hline & FDA, 07I & $200 \mathrm{mg}$ bid & $\begin{array}{l}\text { diclofenac } 75 \text { mg bid; } \\
\text { ibuprofen } 800 \text { mg tid }\end{array}$ & $\mathrm{I}, 097$ & unk & $O A$ and $R A$ & $4,8,12$ weeks \\
\hline & Goldstein ${ }^{69}$ & $200 \mathrm{mg}$ bid & naproxen $500 \mathrm{mg}$ bid & 537 & 57 & $O A$ and $R A$ & $4,8,12$ weeks \\
\hline & $\operatorname{Simon}^{71}$ & $\begin{array}{l}100 \mathrm{mg} \text { bid, } 200 \mathrm{mg} \text { bid, } \\
400 \mathrm{mg} \text { bid }\end{array}$ & $\begin{array}{l}\text { naproxen } 500 \text { mg bid; } \\
\text { placebo }\end{array}$ & $\mathrm{I}, 149$ & 54 & RA & $2,6,12$ weeks \\
\hline & Rofecoxib & & & & & & \\
\hline & Hawkey ${ }^{73}$ & $25 \mathrm{mg} /$ day, $50 \mathrm{mg}$ day & ibuprofen 800 mg tid & 775 & 62 & $O A$ & 6 weeks, 3,6 months \\
\hline & Hawkey $^{74}$ & $50 \mathrm{mg} /$ day & $\begin{array}{l}\text { naproxen } 500 \text { mg bid; } \\
\text { placebo }\end{array}$ & 660 & 51.7 & RA & $3,6,9,12$ weeks \\
\hline & Laine $^{72}$ & $25 \mathrm{mg} /$ day, $50 \mathrm{mg} /$ day & ibuprofen 800 mg tid & 742 & 62 & OA & 6 weeks, 3,6 months \\
\hline & Etoricoxib & & & & & & \\
\hline & Hunt $^{78}$ - multiple & 120 mg/day & ibuprofen 800 mg tid & 680 & 62 & OA & $3,6,9,12$ weeks \\
\hline & $\begin{array}{l}\text { Hunt }^{79}- \\
\text { naproxen }\end{array}$ & $120 \mathrm{mg} /$ day & $\begin{array}{l}\text { naproxen } 500 \text { mg bid; } \\
\text { placebo }\end{array}$ & 742 & 54 & $O A$ and $R A$ & $3,6,9,12$ weeks \\
\hline & Valdecoxib & & & & & & \\
\hline & FDA 047 & $20 \mathrm{mg}$ bid, $40 \mathrm{mg}$ bid & naproxen $500 \mathrm{mg}$ bid & 1,217 & 56 & $O A$ and $R A$ & 26 weeks \\
\hline & FDA 063 & $10 \mathrm{mg} /$ day, $20 \mathrm{mg} /$ day & diclofenac $75 \mathrm{mg}$ bid & 784 & unk & OA & I, 2, 4, 6 weeks \\
\hline & Kivitz $^{80}$ & $\begin{array}{l}5 \mathrm{mg} / \text { day, } 10 \mathrm{mg} / \text { day, } \\
20 \mathrm{mg} / \text { day }\end{array}$ & $\begin{array}{l}\text { naproxen } 500 \text { mg tid; } \\
\text { placebo }\end{array}$ & 1,019 & 60 & OA & $2,6,12$ weeks \\
\hline & Sikes $^{76}$ & $10 \mathrm{mg} /$ day, $20 \mathrm{mg} /$ day & $\begin{array}{l}\text { ibuprofen } 800 \text { mg tid; } \\
\text { diclofenac } 75 \text { mg bid; } \\
\text { placebo }\end{array}$ & 1,052 & 60 & OA & $2,6,12$ weeks \\
\hline & Lumiracoxib & & & & & & \\
\hline & Hawkey ${ }^{74,113}$ & $\begin{array}{l}\text { lumiracoxib } 200 \text { mg/day, } \\
400 \text { mg/day; celecoxib } \\
200 \text { mg/day }\end{array}$ & ibuprofen 800 mg tid & 1,042 & 58.7 & OA & $4,8,13$ weeks \\
\hline & Kivitz $^{81}$ & $\begin{array}{l}\text { lumiracoxib } 400 \text { mg/day, } \\
800 \text { mg/day; celecoxib } \\
200 \text { mg bid }\end{array}$ & ibuprofen 800 mg tid & 893 & 51.7 & RA & 8,13 weeks \\
\hline \multirow{8}{*}{$\begin{array}{l}\text { Clinical ulcer } \\
\text { complications }\end{array}$} & Celecoxib & & & & & & \\
\hline & $\begin{array}{l}\text { Goldstein }{ }^{92} \text { com- } \\
\text { bined analysis } \\
\text { study }\end{array}$ & $25 \mathrm{mg}$ bid to $400 \mathrm{mg}$ bid & $\begin{array}{l}\text { naproxen } 500 \text { mg bid; } \\
\text { diclofenac } 75 \text { mg bid; } \\
\text { ibuprofen } 800 \text { mg tid; } \\
\text { placebo }\end{array}$ & 11,008 & 59 & $O A$ and $R A$ & 2 to 24 weeks \\
\hline & Silverstein ${ }^{82}$ & $400 \mathrm{mg}$ bid & $\begin{array}{l}\text { diclofenac } 75 \text { mg bid; } \\
\text { iboprofen } 800 \text { mg tid }\end{array}$ & 8,059 & 60 & $O A$ and $R A$ & $\begin{array}{l}4,13,26 \text { weeks } \\
\text { (I year FDA) }\end{array}$ \\
\hline & Singh' Success-I & $100 \mathrm{mg}$ bid, $200 \mathrm{mg}$ bid & naproxen 500 mg bid & 13,274 & 62 & OA & 6,12 weeks \\
\hline & Zhao ${ }^{89}$ & $\begin{array}{l}50 \mathrm{mg} \text { bid, } 100 \mathrm{mg} \text { bid, } \\
200 \mathrm{mg} \text { bid }\end{array}$ & $\begin{array}{l}\text { naproxen } 500 \text { mg bid: } \\
\text { placebo }\end{array}$ & $\mathrm{I}, 004$ & 62.2 & OA & $2,6,12$ weeks \\
\hline & Rofecoxib & & & & & & \\
\hline & Bombardier ${ }^{83}$ & $50 \mathrm{mg} /$ day & naproxen 500 mg bid & 8,076 & 58 & RA & $4,8,12$ months \\
\hline & Geusens ${ }^{90}$ & $25 \mathrm{mg} /$ day, $50 \mathrm{mg} /$ day & $\begin{array}{l}\text { naproxen } 500 \text { mg bid; } \\
\text { placebo }\end{array}$ & $\mathrm{I}, 023$ & 53.6 & RA & $2,4,8,12$ weeks \\
\hline
\end{tabular}

(Continued) 
Table 2 (Continued)

\begin{tabular}{|c|c|c|c|c|c|c|c|}
\hline \multirow[t]{2}{*}{ Endpoint } & \multirow[t]{2}{*}{ Study } & \multicolumn{2}{|l|}{ Comparisons } & \multirow{2}{*}{$\begin{array}{l}\text { Number } \\
\text { of patients }\end{array}$} & \multirow{2}{*}{$\begin{array}{l}\text { Mean } \\
\text { age }\end{array}$} & \multirow{2}{*}{$\begin{array}{l}\text { Arthritis } \\
\text { type }\end{array}$} & \multirow[t]{2}{*}{ Follow-up } \\
\hline & & Intervention & Comparator & & & & \\
\hline & $\begin{array}{l}\text { Langman }^{66} \\
\text { combined } \\
\text { analysis study }\end{array}$ & 25 mg/day, 50 mg/day & $\begin{array}{l}\text { ibuprofen } 800 \mathrm{mg} \text { tid; } \\
\text { diclofenac } 50 \mathrm{mg} \text { tid; } \\
\text { nabumetone } \\
\text { I,500 mg/day }\end{array}$ & 5,435 & 63 & OA & $\begin{array}{l}6 \text { weeks, } 4,6,12 \text {, } \\
24 \text { months }\end{array}$ \\
\hline & Lisse $^{88}$ & $25 \mathrm{mg} /$ day & naproxen $500 \mathrm{mg}$ bid & 5,597 & 63 & OA & $3,6,9,12$ weeks \\
\hline & Saag ${ }^{101}$ & 12.5 mg/day, 25 mg/day & ibuprofen $800 \mathrm{mg}$ tid & 736 & 61 & OA & $2,4,6$ weeks \\
\hline & Saag ${ }^{101}$ & $12.5 \mathrm{mg} /$ day, $25 \mathrm{mg} /$ day & diclofenac $50 \mathrm{mg}$ tid & 693 & 62 & OA & up to I year \\
\hline & Etoricoxib & & & & & & \\
\hline & Leung ${ }^{87}$ & $60 \mathrm{mg} /$ day & $\begin{array}{l}\text { naproxen } 500 \text { mg bid; } \\
\text { placebo }\end{array}$ & 501 & 63 & OA & $2,4,8,12$ weeks \\
\hline & $\begin{array}{l}\text { Ramey }^{68} \\
\text { combined } \\
\text { analysis study }\end{array}$ & 5 to $120 \mathrm{mg} /$ day & $\begin{array}{l}\text { diclofenac } 150 \text { mg/day; } \\
\text { naproxen } 1000 \text { mg/day; } \\
\text { ibuprofen } 2400 \text { mg/day }\end{array}$ & $5,44 I$ & 56.7 & $\mathrm{OA}$ and $\mathrm{RA}$ & up to 190 weeks \\
\hline & Laine ${ }^{16}$ MEDAL & 60 or $90 \mathrm{mg} /$ day & diclofenac 150 mg/day & 34701 & 63 & $\mathrm{OA}$ and $\mathrm{RA}$ & up to 36 months \\
\hline & Valdecoxib & & & & & & \\
\hline & $\begin{array}{l}\text { Goldstein }^{92} \\
\text { combined } \\
\text { analysis study }\end{array}$ & 5 to $80 \mathrm{mg} /$ day & $\begin{array}{l}\text { naproxen } 500 \text { mg bid; } \\
\text { diclofenac } 75 \text { mg bid; } \\
\text { ibuprofen } 800 \text { mg tid; } \\
\text { placebo }\end{array}$ & 7,445 & 58.1 & $\mathrm{OA}$ and $\mathrm{RA}$ & up to 26 weeks \\
\hline & Lumiracoxib & & & & & & \\
\hline & $\begin{array}{l}\text { Schnitzer }^{86} \\
\text { TARGET }\end{array}$ & $400 \mathrm{mg} /$ day & $\begin{array}{l}\text { naproxen } 500 \text { mg bid; } \\
\text { ibuprofen } 800 \text { mg tid }\end{array}$ & 18,244 & 63.5 & OA & $\begin{array}{l}4,13,20,26,39 \\
52 \text { weeks }\end{array}$ \\
\hline & COX-2 and PPI & & & & & & \\
\hline & Chan 118 & celecoxib $200 \mathrm{mg}$ bid & $\begin{array}{l}\text { diclofenac } 75 \mathrm{mg}+ \\
\text { omeprazole } 20 \mathrm{mg}\end{array}$ & 287 & 67 & $\mathrm{OA}$ and $\mathrm{RA}$ & 24 weeks \\
\hline & Lai $^{119}$ & celecoxib $200 \mathrm{mg}$ daily & $\begin{array}{l}\text { naproxen } 250 \mathrm{mg} \text { tid + } \\
\text { lansoprosol } 30 \mathrm{mg}\end{array}$ & 142 & 57 & $\mathrm{OA}$ and $\mathrm{RA}$ & 24 weeks \\
\hline & Chan ${ }^{120}$ & celecoxib $200 \mathrm{mg}$ bid & $\begin{array}{l}\text { celecoxib } 200 \mathrm{mg} \text { bid; } \\
\text { esomeprazole } \\
20 \mathrm{mg} \text { bid }\end{array}$ & 271 & 71 & $\mathrm{OA}$ and $\mathrm{RA}$ & 52 weeks \\
\hline \multirow[t]{9}{*}{ Tolerability } & Celecoxib & & & & & & \\
\hline & Bensen ${ }^{95}$ & $\begin{array}{l}50 \mathrm{mg} \text { bid, } 100 \mathrm{mg} \text { bid, } \\
200 \mathrm{mg} \text { bid }\end{array}$ & $\begin{array}{l}\text { naproxen } 500 \text { mg bid; } \\
\text { placebo }\end{array}$ & 1,003 & 62 & OA & $2,6,12$ weeks \\
\hline & Geba $^{102}$ & $\begin{array}{l}\text { celecoxib } 200 \mathrm{mg} / \text { day; } \\
\text { rofecoxib } 12.5 \mathrm{mg} / \text { day, } \\
25 \mathrm{mg} / \text { day }\end{array}$ & $\begin{array}{l}\text { acetaminophen } \\
4000 \mathrm{mg} / \text { day }\end{array}$ & 382 & 63 & OA & 2, 4, 6 weeks \\
\hline & Kivitz $^{122}$ & $\begin{array}{l}100 \text { mg/day, } 200 \text { mg/day, } \\
400 \text { mg/day }\end{array}$ & $\begin{array}{l}\text { naproxen } 500 \text { mg bid; } \\
\text { placebo }\end{array}$ & $|, 06|$ & 62.6 & OA & $2,6,12$ weeks \\
\hline & McKenna ${ }^{104}$ & $100 \mathrm{mg}$ bid & $\begin{array}{l}\text { diclofenac } 50 \mathrm{mg} \text { tid; } \\
\text { placebo }\end{array}$ & 600 & 62 & OA & 2,6 weeks \\
\hline & McKenna ${ }^{105}$ & $\begin{array}{l}\text { celecoxib } 200 \mathrm{mg} / \text { day; } \\
\text { rofecoxib } 25 \mathrm{mg} / \text { day }\end{array}$ & placebo & 182 & 62 & OA & 3,6 weeks \\
\hline & Whelton ${ }^{103}$ & $\begin{array}{l}\text { celecoxib } 200 \mathrm{mg} / \text { day; } \\
\text { rofecoxib } 25 \mathrm{mg} / \text { day }\end{array}$ & none & 811 & 74 & OA & I, 2, 6 weeks \\
\hline & Williams $^{94}$ & $200 \mathrm{mg} /$ day & placebo & 686 & 63 & OA & 2,6 weeks \\
\hline & Williams $^{142}$ & 100 mg bid, 200 mg/day & placebo & 718 & 61.5 & OA & 2,6 weeks \\
\hline
\end{tabular}


Table 2 (Continued)

\begin{tabular}{|c|c|c|c|c|c|c|c|}
\hline \multirow[t]{2}{*}{ Endpoint } & \multirow[t]{2}{*}{ Study } & \multicolumn{2}{|l|}{ Comparisons } & \multirow{2}{*}{$\begin{array}{l}\text { Number } \\
\text { of patients }\end{array}$} & \multirow{2}{*}{$\begin{array}{l}\text { Mean } \\
\text { age }\end{array}$} & \multirow{2}{*}{$\begin{array}{l}\text { Arthritis } \\
\text { type }\end{array}$} & \multirow[t]{2}{*}{ Follow-up } \\
\hline & & Intervention & Comparator & & & & \\
\hline & \multicolumn{7}{|l|}{ Rofecoxib } \\
\hline & Cannon ${ }^{98}$ & $12.5 \mathrm{mg} /$ day $25 \mathrm{mg} /$ day & diclofenac $50 \mathrm{mg}$ tid & 784 & 64 & OA & up to I year \\
\hline & Day ${ }^{97}$ & $12.5 \mathrm{mg} /$ day, $25 \mathrm{mg} /$ day & ibuprofen $800 \mathrm{mg}$ tid & 809 & 64 & OA & 2, 4, 6 weeks \\
\hline & Ehrich ${ }^{99}$ & 25 to $125 \mathrm{mg} /$ day & placebo & 219 & 64 & OA & I, 2, 4, 6 weeks \\
\hline & Myllykangas ${ }^{121}$ & $12.5 \mathrm{mg} /$ day & naproxen $500 \mathrm{mg}$ bid & 944 & 61.6 & OA & 2, 4, 6 weeks \\
\hline & Schnitzer ${ }^{100}$ & 5 to $50 \mathrm{mg} /$ day & placebo & 658 & 55 & RA & 2, 4, 8 weeks \\
\hline & Truitt $^{96}$ & $12.5 \mathrm{mg} /$ day, $25 \mathrm{mg} /$ day & nabumetone & 341 & 83 & $\mathrm{OA}$ & I, 2, 4, 6 weeks \\
\hline & & & I500 mg/day; placebo & & & & \\
\hline & \multicolumn{7}{|l|}{ Etoricoxib } \\
\hline & Collantes ${ }^{110}$ & $90 \mathrm{mg} / \mathrm{day}$ & $\begin{array}{l}\text { naproxen } 500 \text { mg bid; } \\
\text { placebo }\end{array}$ & 891 & 52 & RA & $2,4,8,12$ weeks \\
\hline & Gottesdiener ${ }^{108}$ & $\begin{array}{l}\text { Part I: } 5 \text { to } 90 \mathrm{mg} / \text { day } \\
\text { Part 2: } 30 \mathrm{mg} / \text { day, } \\
60 \mathrm{mg} / \text { day } 90 \mathrm{mg} / \text { day }\end{array}$ & $\begin{array}{l}\text { Part I: placebo Part 2: } \\
\text { diclofenac } 50 \mathrm{mg} \text { tid }\end{array}$ & 617 & 60 & OA & I, 2, 4, 6, 8, I 4 weeks \\
\hline & Matsumoto'II & 90 mg/day & $\begin{array}{l}\text { naproxen } 500 \text { mg bid; } \\
\text { placebo }\end{array}$ & 816 & 56 & RA & $2,4,8,12$ weeks \\
\hline & Wiesenhutter ${ }^{123}$ & $30 \mathrm{mg} /$ day & $\begin{array}{l}\text { ibuprofen } 2400 \text { mg/day; } \\
\text { placebo }\end{array}$ & 258 & 61.3 & OA & I, 2, 4, 6 weeks \\
\hline & Zacher $^{109}$ & $60 \mathrm{mg} /$ day & diclofenac $50 \mathrm{mg}$ tid & 516 & 63 & $\mathrm{OA}$ & $2,4,6,8$ weeks \\
\hline & \multicolumn{7}{|l|}{ Valdecoxib } \\
\hline & Bensen $^{107}$ & $\begin{array}{l}10 \mathrm{mg} / \text { day, } 20 \mathrm{mg} / \text { day, } \\
40 \mathrm{mg} / \text { day }\end{array}$ & $\begin{array}{l}\text { naproxen } 500 \text { mg bid; } \\
\text { placebo }\end{array}$ & $\mathrm{I}, 090$ & 55 & RA & $4,8,12$ months \\
\hline & FDA 06I & $\begin{array}{l}10 \mathrm{mg} / \text { day, } 20 \mathrm{mg} / \text { day, } \\
40 \mathrm{mg} / \text { day }\end{array}$ & $\begin{array}{l}\text { naproxen } 500 \text { mg bid; } \\
\text { placebo }\end{array}$ & 1,093 & 57 & RA & 12 weeks \\
\hline & Makarowski ${ }^{106}$ & $5 \mathrm{mg} /$ day, $10 \mathrm{mg} /$ day & $\begin{array}{l}\text { naproxen } 500 \text { mg bid; } \\
\text { placebo }\end{array}$ & 513 & 68 & OA & 3 weeks \\
\hline & Pavelka ${ }^{77}$ & 20 mg/day, 40 mg/day & diclofenac $75 \mathrm{mg}$ bid & 722 & 56 & RA & $\begin{array}{l}2,6,8,12,18 \\
26 \text { weeks }\end{array}$ \\
\hline & \multicolumn{7}{|l|}{ Lumiracoxib } \\
\hline & Geusens $^{124}$ & 200 mg/day, 400 mg/day & naproxen $500 \mathrm{mg}$ bid & $\mathrm{I}, 124$ & 71 & RA & $2,4,13,20,26$ weeks \\
\hline & Grifka $^{125}$ & 200 mg/day, 400 mg/day & placebo & 594 & 61.9 & OA & 2, 4, 6 weeks \\
\hline & Lehmann $^{126}$ & $\begin{array}{l}100 \mathrm{mg} / \text { day, } 100 \mathrm{mg} / \text { day } \\
\text { with } 200 \mathrm{mg} \text { loading } \\
\text { dose for first } 2 \text { weeks; } \\
\text { celecoxib } 200 \mathrm{mg} / \text { day }\end{array}$ & placebo & 1,684 & 62.4 & OA & $2,4,8,13$ weeks \\
\hline & Schnitzer ${ }^{86}$ & $\begin{array}{l}50 \mathrm{mg} \text { bid, } 100 \mathrm{mg} \text { bid, } \\
200 \mathrm{mg} \text { bid, } 400 \mathrm{mg} \text { bid }\end{array}$ & $\begin{array}{l}\text { diclofenac } 400 \text { mg bid; } \\
\text { placebo }\end{array}$ & 583 & 60.3 & $\mathrm{OA}$ & 4 weeks \\
\hline & Schnitzer ${ }^{86}$ & $\begin{array}{l}50 \mathrm{mg} \text { bid, } 100 \mathrm{mg} \text { bid, } \\
200 \mathrm{mg} \text { bid, } 400 \mathrm{mg} \text { bid }\end{array}$ & $\begin{array}{l}\text { diclofenac } 400 \text { mg bid; } \\
\text { placebo }\end{array}$ & 569 & 54.4 & RA & $2,6,12$ weeks \\
\hline & Tannenbaum ${ }^{141}$ & $\begin{array}{l}\text { lumiracoxib } 200 \text { mg/day, } \\
400 \text { mg/day; celecoxib } \\
200 \text { mg/day }\end{array}$ & placebo & $\mathrm{I}, 702$ & 64.3 & OA & $2,4,8,13$ weeks \\
\hline
\end{tabular}

Abbreviations: unk, unknown; OA, osteoarthritis; PPI, protein pump inhibitors; RA, rheumatoid arthritis. 


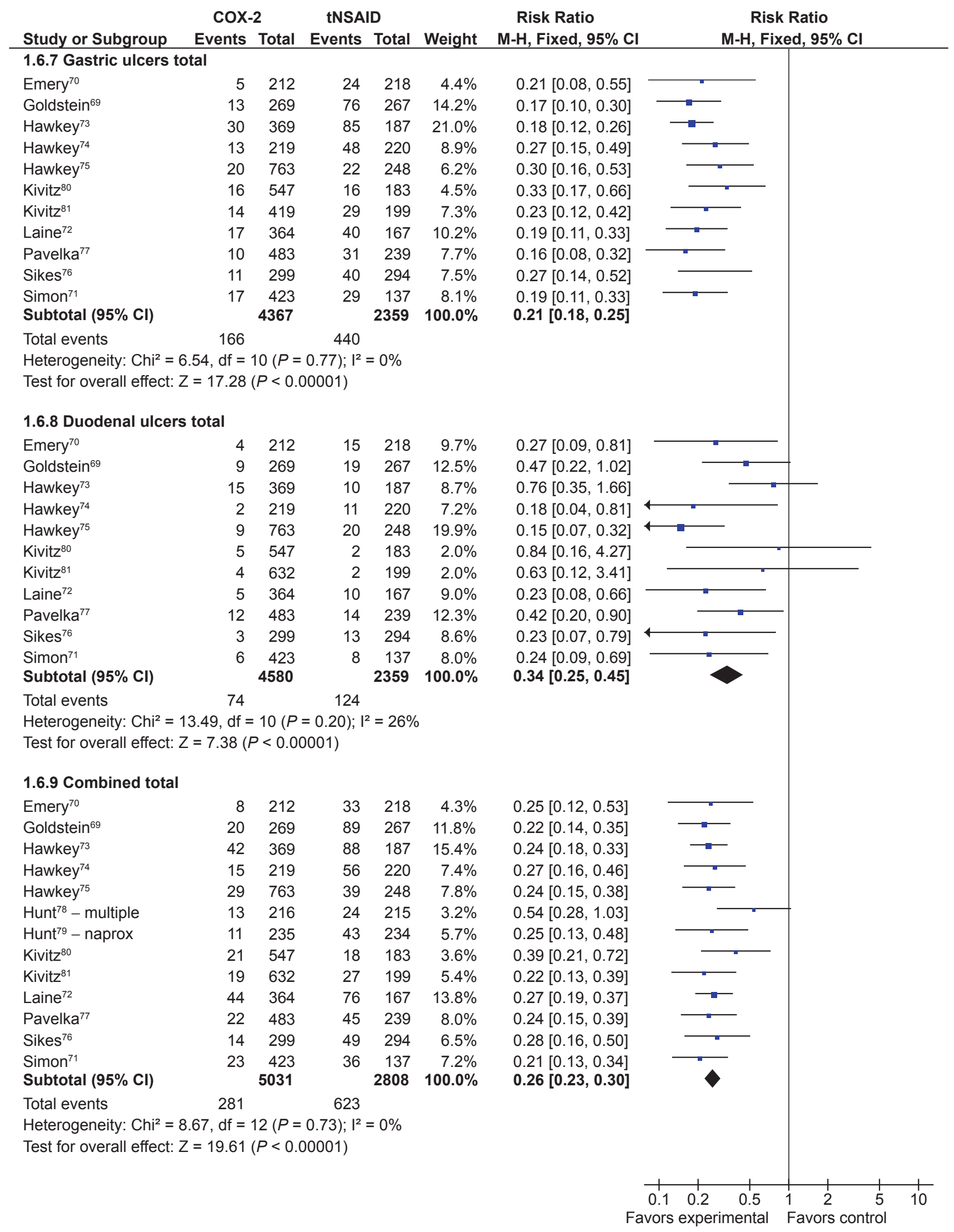

Figure 7 COX-2 vs tNSAID for endoscopic ulcers with any COX-2 dose. 


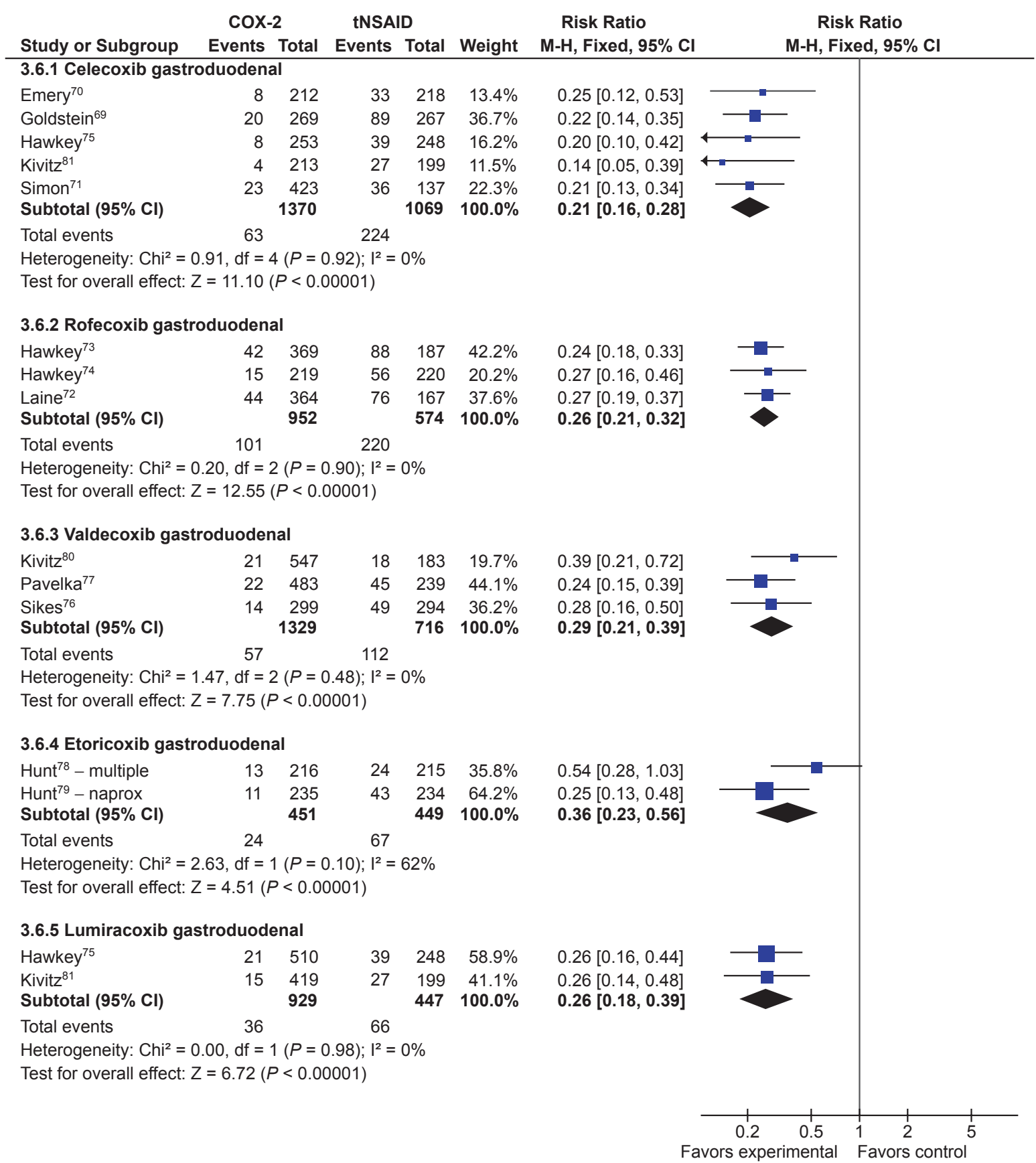

Figure 8 Gastroduodenal ulcers analysed by individual COX-2 inhibitor compared to tNSAIDs.

\section{Etoricoxib}

Two studies, with a total of 900 patients compared etoricoxib to non-selective NSAIDs using the endpoint of endoscopic gastro-duodenal ulcers. ${ }^{78,79}$ These trials demonstrated a $64 \%$ RRR (RR 0.37 ; $95 \%$ CI 0.18 to 0.77 , random effects) with etoricoxib.

\section{Valdecoxib}

Three studies compared valdecoxib to non-selective NSAIDs in 2,045 patients and demonstrated a 70\% RRR in gastro-duodenal ulcers (RR $0.29 ; 95 \%$ CI 0.21 to 0.39 ) with valdecoxib. ${ }^{76,77,80}$ Similar RRR were observed when the analysis was done for gastric ulcers (RR $0.24 ; 95 \%$ CI $0.18-0.37$ ) and duodenal ulcers alone (RR 0.39; 95\% CI 0.21 to 0.70 ), and when the FDA studies were included in the gastro-duodenal ulcers analysis (RR 0.30 ; $95 \%$ CI 0.24 to 0.39 ).

\section{Lumiracoxib}

Two studies with a total of 1,376 patients compared lumiracoxib to non-selective NSAIDs. ${ }^{112,113}$ Lumiracoxib was 
associated with a $74 \%$ RRR in gastro-duodenal ulcers (RR 0.26; 95\% CI 0.18 to 0.39). Similar results were observed for gastric ulcers (RR 0.25 ; 95\% CI 0.16 to 0.40 ) and duodenal ulcers (RR $0.20 ; 95 \%$ CI 0.09 to 0.43 ) when they were considered alone.

\section{Analysis by comparator NSAIDs Naproxen}

Five studies compared either celecoxib or valdecoxib to naproxen in 2,734 patients. These showed a 75\% RRR in endoscopic gastro-duodenal ulcers in favor of the COX-2s (RR 0.25 ; 95\% CI 0.20 to 0.32 ). Results were similar when the FDA studies were included in the analysis (RR $0.27 ; 95 \%$ CI: 0.22 to 0.32$){ }^{69,71,74,79,80}$

\section{Ibuprofen}

Six studies which enrolled over 3,800 patients ( 2 rofecoxib, ${ }^{72,73}$ 1 etoricoxib, ${ }^{78} 2$ lumiracoxib, ${ }^{112,113}$ and 1 valdecoxib ${ }^{76}$ ) showed a 73\% RRR in gastro-duodenal ulcers with COX-2s compared with ibuprofen (RR 0.27 ; 95\% CI 0.23 to 0.32 ). Results were similar when the FDA studies were included in the analysis (RR $0.28 ; 95 \%$ CI 0.23 to 0.32 ).

\section{Diclofenac}

Three studies which enrolled a total of 1,596 patients demonstrated a 75\% RRR in gastro-duodenal ulcers with COX-2s compared to diclofenac (RR 0.25 ; 95\% CI 0.18 to 0.35 ). This effect was somewhat reduced when the FDA studies were included in the analysis (RR 0.36; 95\% CI 0.27 to 0.47$){ }^{70,76,77}$

Similar results were obtained when individual COX-2s were compared with the individual non-selective NSAIDs.

\section{COX-2s vs placebo}

Eight studies with a total of 4,081 patients compared low- and high-dose COX-2s to placebo. ${ }^{71-74,76,78-80}$ Low dose COX-2s appeared to demonstrate no greater risk of gastric or gastro-duodenal ulcers than placebo. However, high doses of COX-2s appeared to raise the relative risk of gastric (RR 1.22; 95\% CI 0.83 to 1.80), duodenal (RR 1.29; 95\% CI 0.63 to 2.66), and combined gastro-dudenal ulcers (RR 1.57; 95\% CI 0.96 to 2.56, random effects), though these trends missed statistical significance. Clinical GI events COX-2s vs non-selective NSAIDs Nine studies with a total of 94,294 patients assessed the safety of COX-2s by using the clinically important endpoint of ulcer complication, POB. ${ }^{65,66,68,82,83,92,114-116}$ Three of these trials studied celecoxib, ${ }^{82,92,115} 2$ studied rofecoxib, ${ }^{66,83} 2$ trials evaluated etoracoxib, ${ }^{68,116}$ and 1 each evaluated valdecoxib ${ }^{65}$ and lumiracoxib ${ }^{114}$ separately. Overall, the use of these COX-2s was associated with a 57\% RRR in POBs (RR, 0.43; 95\% CI 0.28 to 0.67 , random effects), compared with using tNSAIDs. Removal of the combined analyses studies had no influence on the result (RR $0.39 ; 0.29$ to 0.53 ) and the inclusion of the FDA 12-month CLASS study data ${ }^{117}$ did not alter the results (RR $0.42 ; 95 \%$ CI 0.33 to 0.54 ). The $60 \% \mathrm{RRR}$ in these analyses represents an ARR of $0.4 \%$ (Figure 9).

Fourteen studies compared COX-2s with tNSAIDs by using PUB as the study endpoint. ${ }^{65,66,68,78,82,83,87-90,92,114-116}$ In this analysis, the use of a COX-2 was associated with a 57\% RRR in PUBs (RR 0.43; 95\% CI 0.34 to 0.55 , random effects). Removal of the combined analyses studies eliminated the observed heterogeneity but had little effect on the point estimate (RR $0.49 ; 95 \%$ CI 0.41 to 0.58 ). Similarly, the use of the FDA CLASS data did not significantly alter the estimate (RR $0.42 ; 95 \%$ CI 0.33 to 0.53 , random effects) (Figure 10).

\section{Analyses stratified by cyclooxygenase-2s Celecoxib}

Four studies with 31,106 assessed the effect celecoxib vs non-selective NSAIDs on clinical GI events (POBs or PUBs). ${ }^{82,89,92}$ Celecoxib use was associated with a $77 \%$ RRR in POBs (RR 0.23; 95\% CI 0.07 to 0.76 , random effects) and a $61 \%$ RRR in PUBs (RR 0.39; 95\% CI 0.21 to 0.73 , random effects). Removal of the combined analyses study ${ }^{92}$ eliminated the heterogeneity observed in both the POB (RR $0.42 ; 95 \%$ CI 0.22 to 0.80$)$ and PUBs (RR $=0.34 ; 95 \%$ CI 0.22 to 0.80 ) analyses. The use of the FDA 12-month CLASS data did not alter the RR estimates for POBs or PUBs significantly.

\section{Rofecoxib}

Four studies with 19,288 patients assessed the effect of rofecoxib vs non-selective NSAIDs on clinical GI events (POBs or PUBs). ${ }^{66,83,88,90}$ Rofecoxib use reduced the relative risk of POBs by $58 \%$ (RR 0.42 ; 95\% CI 0.24 to 0.73 ) and the relative risk of PUBs by $56 \%$ (RR $0.44 ; 95 \%$ CI 0.34 to 0.58). Removal of the combined analysis study did not alter the point estimates.

\section{Valdecoxib}

One combined analysis study with 6,461 patients evaluated the effect of valdecoxib on POBs and PUBs. ${ }^{65}$ Valdecoxib reduced the relative risk of $\mathrm{POBs}$ by $65 \%$ (RR $0.35 ; 95 \%$ CI 0.14 to 0.87 ) and the relative risk of PUBs by $77 \%$ (RR 0.23 ; $95 \% 0.15$ to 0.36 ). 


\begin{tabular}{|c|c|c|c|c|c|}
\hline \multirow[b]{2}{*}{ Study or Subgroup } & \multicolumn{2}{|c|}{ Treatment } & \multicolumn{2}{|c|}{ Control } & \multirow[b]{2}{*}{ Weight } \\
\hline & Events & Total & Events & Total & \\
\hline Goldstein ${ }^{92}$ & 2 & 6376 & 9 & 2768 & $5.5 \%$ \\
\hline Singh ${ }^{91}$ SUCCESS-I & 2 & 8800 & 7 & 4394 & $5.3 \%$ \\
\hline Langman ${ }^{66}$ & 2 & 3357 & 3 & 1564 & $4.4 \%$ \\
\hline Schnitzer ${ }^{114}$ - TARGET & 29 & 9117 & 83 & 9127 & $16.4 \%$ \\
\hline Goldstein ${ }^{65}$ & 8 & 4362 & 11 & 2099 & $10.3 \%$ \\
\hline Bombardier ${ }^{83}$ & 16 & 4047 & 37 & 4029 & $14.2 \%$ \\
\hline Silverstein ${ }^{82}$ & 11 & 3987 & 20 & 3981 & $12.3 \%$ \\
\hline Ramey ${ }^{68}$ & 19 & 3226 & 23 & 2215 & $14.0 \%$ \\
\hline MEDAL & 78 & 17412 & 82 & 17289 & $17.7 \%$ \\
\hline Total $(95 \% \mathrm{Cl})$ & & 60684 & & 47466 & $100.0 \%$ \\
\hline Total events & 167 & & 275 & & \\
\hline $\begin{array}{l}\text { Heterogeneity: } \mathrm{Tau}^{2}=0 \\
\text { Test for overall effect: } Z\end{array}$ & $\begin{array}{l}; \mathrm{Chi}^{2}= \\
3.91(P\end{array}$ & $\begin{array}{r}26.03 \\
0.00\end{array}$ & 2.0 & م0 & \\
\hline
\end{tabular}

Figure 9 POBs (perforation, obstruction or bleeding) with COX-2s vs tNSAIDs.

\section{Etoricoxib}

Four studies with 10,856 patients evaluated the effect of etoricoxib on POBs ${ }^{68,116}$ and PUBs. ${ }^{78,87}$ Etoricoxib demonstrated a nonsignificant trend in reducing the risk of POBs (RR 0.82; 95\% CI 0.44 to 1.51, random effects), but it significantly reduced the RR of PUBs by $46 \%$ (RR 0.64 ; $95 \%$ CI 0.42 to 0.96 ).

\section{Lumiracoxib}

One study with 18,244 patients demonstrated a significant $64 \%$ RRR in POBs (RR 0.36; 95\% CI 0.24 to 0.55 ) and a 44\% RRR in PUBs (RR 0.56; CI 0.41 to 0.78 ) with the use of lumiracoxib, compared with using non-selective NSAIDs. ${ }^{114}$
Risk Ratio

M-H, Random, 95\% Cl

$0.10[0.02,0.45]$

$0.14[0.03,0.69]$

$0.31[0.05,1.86]$

$0.35[0.23,0.53]$

$0.35[0.14,0.87]$

$0.43[0.24,0.77]$

$0.55[0.26,1.14]$

$0.57[0.31,1.04]$

$0.94[0.69,1.29]$

$0.43[0.28,0.66]$

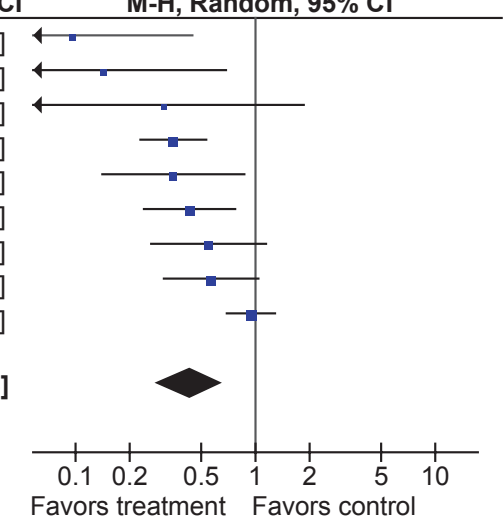

Risk Ratio

M-H, Random, $95 \% \mathrm{Cl}$

Favors treatment Favors control

\section{Analysis by comparator NSAIDs}

In general COX-2s appeared to maintain their safety advantage regardless of the comparator non-selective NSAID. COX-2s were statistically superior to naproxen (RR 0.34; 95\% CI 0.24 to 0.48), and ibuprofen (RR 0.46; 95\% CI 0.30 to 0.71 ) for the POB endpoint. The data comparing COX-2s to diclofenac are predominately derived from 2 studies and heavily influenced by the CLASS trial data which showed no significant difference between celecoxib vs diclofenac. ${ }^{82,92}$ In the current analysis, celecoxib demonstrated a non-significant trend towards fewer POBs than diclofenac (RR $0.31 ; 95 \%$ CI 0.06 to 1.61 ) while a statistically significant 59\% RRR in PUBs was observed (RR 0.41 ; $95 \%$ CI 0.30 to 0.55 ).

\begin{tabular}{|c|c|c|c|c|c|c|c|c|c|}
\hline \multirow{3}{*}{$\begin{array}{l}\text { Study or Subgroup } \\
\text { Bombardier }\end{array}$} & \multicolumn{2}{|c|}{ Treatment } & \multicolumn{2}{|c|}{ Control } & \multirow[b]{2}{*}{ Weight } & Risk Ratio & \multirow{2}{*}{\multicolumn{3}{|c|}{$\begin{array}{c}\text { Risk Ratio } \\
\text { M-H, Random, } 95 \% \mathrm{CI}\end{array}$}} \\
\hline & Events & Total & Events & Total & & M-H, Random, 95\% Cl & & & \\
\hline & 56 & 4047 & 121 & 4029 & $11.5 \%$ & $0.46[0.34,0.63]$ & & & \\
\hline Geusens $^{90}$ & 1 & 592 & 4 & 142 & $1.1 \%$ & $0.06[0.01,0.53]$ & & & \\
\hline Goldstein ${ }^{92}$ & 12 & 6376 & 26 & 2768 & $6.6 \%$ & $0.20[0.10,0.40]$ & & & \\
\hline Goldstein ${ }^{65}$ & 28 & 4362 & 58 & 2099 & $9.5 \%$ & $0.23[0.15,0.36]$ & & & \\
\hline Hunt $^{78}$ - multiple & 30 & 3142 & 41 & 1828 & $9.2 \%$ & $0.43[0.27,0.68]$ & & & \\
\hline Langman ${ }^{66}$ & 19 & 3357 & 16 & 1564 & $6.8 \%$ & $0.55[0.29,1.07]$ & & & \\
\hline Leung $^{87}$ & 0 & 224 & 5 & 221 & $0.7 \%$ & $0.09[0.00,1.61]$ & $\leftarrow$ & & \\
\hline Lisse $^{88}$ & 2 & 2785 & 9 & 2772 & $2.1 \%$ & $0.22[0.05,1.02]$ & & & \\
\hline MEDAL & 176 & 17412 & 246 & 17289 & $13.1 \%$ & $0.71[0.59,0.86]$ & - & & \\
\hline Ramey ${ }^{68}$ & 40 & 3226 & 55 & 2215 & $10.2 \%$ & $0.50[0.33,0.75]$ & & & \\
\hline Schnitzer ${ }^{114}$ - TARGET & 87 & 9117 & 186 & 9127 & $12.3 \%$ & $0.47[0.36,0.60]$ & & & \\
\hline Silverstein ${ }^{82}$ & 30 & 3987 & 49 & 3981 & $9.5 \%$ & $0.61[0.39,0.96]$ & & & \\
\hline Singh ${ }^{91}$ SUCCESS-I & 18 & 8800 & 18 & 4394 & $6.9 \%$ & $0.50[0.26,0.96]$ & & & \\
\hline Zhao ${ }^{89}$ & 0 & 602 & 1 & 198 & $0.5 \%$ & $0.11[0.00,2.69]$ & $\leftarrow$ & & \\
\hline Total $(95 \% \mathrm{Cl})$ & & 68029 & & 52627 & $100.0 \%$ & $0.43[0.34,0.54]$ & & & \\
\hline Total events & 499 & & 835 & & & & & & \\
\hline $\begin{array}{l}\text { Heterogeneity: } \mathrm{Tau}^{2}=0 \\
\text { Test for overall effect: } \mathbf{Z}\end{array}$ & $\begin{array}{l}\text { 10; } \text { Chi }^{2}= \\
=6.93(P\end{array}$ & $\begin{array}{l}39.65, c \\
<0.000 c\end{array}$ & $\mathrm{ff}=13(P$ & $=0.000$ & $2) ; I^{2}=67 \%$ & & $\begin{array}{lll}0.1 & 0.2 & 0.5 \\
\text { Favors } & \end{array}$ & $\begin{array}{lrr}1 & 2 & 1 \\
\text { Favors control }\end{array}$ & $\begin{array}{l}1 \\
5 \\
5\end{array}$ \\
\hline
\end{tabular}

Figure 10 PUBs (POBs [perforation, obstruction or bleeding] or symptomatic ulcer) with COX-2s vs tNSAIDs. 


\section{COX-2s vs placebo}

There are limited data, mostly derived from the combined analyses studies, comparing COX-2s with placebo for the clinical outcomes of $\mathrm{POBs}^{65,92}$ and PUBs. ${ }^{65,66,87,89,92}$ In these analyses, the use of COX-2s was associated with non-significant trends toward an increased RR of POBs (RR 2.66; 95\% CI 0.34 to 20.95) and PUBs (RR 2.26; 95\% CI 0.96 to 5.33 ) (Figure 9). These findings are supported by the APPROVe polyp prevention study which demonstrated that over a 3-year period, rofecoxib was associated with a statistically significant 4.9-fold increased risk of clinical ulcer complications compared to placebo. ${ }^{9}$ This study was not included in the main results since its population did not include arthritis patients.

\section{Influence of acetylsalicylic acid co-administration on clinically important ulcer complications}

Five trials allowed assessment of the effects of the co-administration of ASA with a COX-2. ${ }^{65,82,91,114,116}$ In a pooled subgroup analysis of over 18,000 patients taking ASA, there was no statistically significant difference in the relative risk of ulcer complications (POBs) between those in the COX-2 arms and those in the non-selective arms of these trials (RR $0.93 ; 95 \%$ CI 0.68 to 1.27 for POBs). A small advantage of COX-2s over tNSAIDs cannot be ruled out by these results because this subgroup analysis might be underpowered The PUB analysis showed a statistically significant benefit for COX-2 + ASA vs tNSAID +ASA (RR 0.72; $95 \%$ CI 0.62 to 0.95 ), but data from one study could not be used in this analysis. In more than 40,000 patients in the COX-2 arms, patients taking ASA had a 3.46 (95\% CI 2.44 to 4.91) greater relative risk of POBs than COX-2 users not taking ASA. Among 34,000 patients in the tNSAID arms of these studies, those taking ASA had a 1.65 greater relative risk of POBs than those not taking ASA, although this result did not reach statistical significance (95\% CI 0.76 to 3.57$)$. One must keep in mind that these are post-hoc subgroup analyses that might be subject to bias. Furthermore, the subgroup analysis within an tNSAID treatment group (eg, COX-2 vs COX-2 + ASA) represents a nonrandomized comparison in which differences could be influenced by factors other than ASA use (Figures 11 to 13).

\section{Addition of a PPI to COX-2s}

The comparative safety of a COX-2s compared to a tNSAID with a PPI has been addressed in high-risk patients with recent ulcer bleeding who were enrolled after ulcer healing and H. pylori eradication. Chan et $\mathrm{al}^{118}$ found recurrent ulcer bleeding at 6 months to be $4.9 \%$ with celecoxib $200 \mathrm{mg}$ twice daily and $6.4 \%$ with diclofenac $75 \mathrm{mg}$ twice daily plus omeprazole $20 \mathrm{mg}$ daily. Lai et $\mathrm{al}^{119}$ found recurrent ulcer complications (bleeding and 1 case of severe pain) in $3.7 \%$ with celecoxib $200 \mathrm{mg}$ daily and $6.3 \%$ with naproxen $750 \mathrm{mg}$ daily plus lansoprazole $30 \mathrm{mg}$ daily at a median follow-up of 24 weeks. These results suggest high-risk patients have high rates of recurrent bleeding even with the protective strategy of a coxib or a tNSAID + PPI.

The combination of a coxib and PPI was assessed in the same high-risk population in a subsequent 1-year study by Chan et al ${ }^{120}$ Recurrent ulcer bleeding occurred in 9\% with celecoxib alone vs zero with celecoxib plus twice daily esomeprazole. The MEDAL Program also demonstrated that a coxib plus PPI had significantly fewer upper GI clinical events (again, driven by a decrease in uncomplicated events) than a tNSAID plus PPI (RR 0.62, 0.45 to 0.83$).{ }^{116}$

\section{Symptoms and treatment withdrawals}

Treatment withdrawals as a result of GI side effects: COX-2s vs nonselective NSAIDs.

Twenty-one studies with close to 47,000 patients assessed the effect of COX-2s on patient withdrawals due to GI symptoms. ${ }^{61,69-71,79,82,83,87-90,95,98,101,106,109,110,111,115,121-123}$ Overall, compared to tNSAIDs, COX-2s were associated with a significantly lower relative risk of withdrawals due to GI

\begin{tabular}{|c|c|c|c|c|c|c|c|}
\hline Study or Subgroup & $\begin{array}{l}\text { Treatm } \\
\text { Events }\end{array}$ & $\begin{array}{l}\text { ent } \\
\text { Total }\end{array}$ & $\begin{array}{l}\text { Contr } \\
\text { Events }\end{array}$ & $\begin{array}{l}\text { rol } \\
\text { Total }\end{array}$ & Weight & $\begin{array}{l}\text { Risk Ratio } \\
\text { M-H, Fixed, } 95 \% \mathrm{Cl}\end{array}$ & $\begin{array}{c}\text { Risk Ratio } \\
\text { M-H, Fixed, } 95 \% \text { CI }\end{array}$ \\
\hline MEDAL 2007 & 100 & 5752 & 124 & 5680 & $64.8 \%$ & $0.80[0.61,1.03]$ & \\
\hline Schnitzer ${ }^{114}$ - TARGET & 33 & 2167 & 45 & 2159 & $23.4 \%$ & $0.73[0.47,1.14]$ & \\
\hline Silverstein 82 & 14 & 298 & 17 & 283 & $9.1 \%$ & $0.78[0.39,1.56]$ & \\
\hline Singh ${ }^{91}$ SUCCESS-I & 3 & 622 & 4 & 315 & $2.8 \%$ & $0.38[0.09,1.69]$ & \\
\hline Total $(95 \% \mathrm{Cl})$ & & 8839 & & 8437 & $100.0 \%$ & $0.77[0.62,0.95]$ & \\
\hline Total events & 150 & & 190 & & & & \\
\hline \multicolumn{7}{|c|}{$\begin{array}{l}\text { Heterogeneity: } \mathrm{Chi}^{2}=0.98, \mathrm{df}=3(P=0.81) ; I^{2}=0 \% \\
\text { Test for overall effect: } Z=2.44(P=0.01)\end{array}$} & 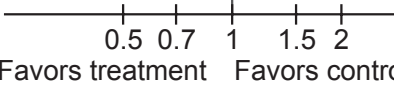 \\
\hline
\end{tabular}

Figure II Clinical ulcers (PUBs [perforation, obstruction, bleeding or the presence of a symptomatic ulcer]) with COX-2 + ASA vs tNSAID + ASA. Note: This is a non-randomized comparison. 


\begin{tabular}{|c|c|c|c|c|c|c|c|c|}
\hline Study or Subgroup & \multicolumn{2}{|c|}{ Treatment } & \multicolumn{2}{|c|}{ Control } & Weight & $\begin{array}{c}\text { Risk Ratio } \\
\text { M-H, Fixed, 95\% Cl }\end{array}$ & \multicolumn{2}{|c|}{$\begin{array}{c}\text { Risk Ratio } \\
\text { M-H, Fixed, 95\% Cl }\end{array}$} \\
\hline MEDAL & 100 & 5752 & 76 & 11660 & $59.3 \%$ & $2.67[1.98,3.59]$ & & \\
\hline Schnitzer ${ }^{114}$ - TARGET & 33 & 2167 & 54 & 6950 & $30.3 \%$ & $1.96[1.27,3.01]$ & & \\
\hline Silverstein ${ }^{82}$ & 14 & 298 & 16 & 1143 & $7.8 \%$ & $3.36[1.66,6.80]$ & & \\
\hline Singh ${ }^{91}$ SUCCESS-I & 3 & 622 & 15 & 8178 & $2.5 \%$ & $2.63[0.76,9.06]$ & & \\
\hline Total $(95 \% \mathrm{Cl})$ & & 8839 & & 27931 & $100.0 \%$ & $2.51[2.00,3.14]$ & & \\
\hline Total events & 150 & & 161 & & & & & \\
\hline $\begin{array}{l}\text { Heterogeneity: } \mathrm{Chi}^{2}=2 . \\
\text { Test for overall effect: } \mathrm{Z}\end{array}$ & $\begin{array}{l}9, \mathrm{df}=3 \\
=7.94(P\end{array}$ & $\begin{array}{l}(P=0.5 \\
<0.000\end{array}$ & $\begin{array}{l}55) ;\left.\right|^{2}=0 \\
\text { 01) }\end{array}$ & & & & $\begin{array}{r}0.50 .7 \\
\text { Favors treatment }\end{array}$ & $\begin{array}{l}1.52 \\
\text { Favors con }\end{array}$ \\
\hline
\end{tabular}

Figure 12 Clinical ulcers (PUBs [perforation, obstruction, bleeding or the presence of a symptomatic ulcer]) with COX-2 + ASA vs COX-2 alone. Note: This is a non-randomized comparison.

side effects (RR $0.65 ; 95 \%$ CI 0.57 to 0.73 , random effects), withdrawals due to dyspepsia (RR 0.37 ; $95 \%$ CI 0.18 to 0.74), and due to abdominal pain (RR 0.25 ; 95\% CI 0.13 to 0.49 ). Compared to placebo, low-dose COX-2s showed no statistically significant difference for these same endpoints, while high-dose COX-2s were associated with a small but significantly increased relative risk of drop-outs due to GI side effects (RR 1.74; 95\% CI 1.13 to 2.68).

\section{Adverse Gl symptoms with COX-2s compared with non-selective NSAIDs}

Twenty-eight studies with close to 60,000 patients assessed the effect of low- or high-dose COX-2s compared to tNSAIDs for treatment related overall GI side effects, dyspepsia, nausea, and

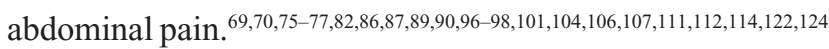
Low-dose COX-2s were associated with a lower relative risk of GI symptoms (RR 0.78; 95\% CI 0.74 to 0.82 ); dyspepsia (RR 0.83; 95\% CI 0.75 to 0.90 ); nausea (RR 0.72; 95\% CI 0.64 to 0.82 ); and abdominal pain (RR $0.64 ; 95 \%$ CI 0.58 to 0.70). The results for high-dose COX-2s were similar.

\section{Adverse GI symptoms with COX-2s compared with placebo}

Twenty studies with over 10,000 patients compared the occurrence of adverse GI symptoms between COX-2s and placebo. Low-dose COX-2s were associated with a slight but statistically significant increased relative risk of overall GI symptoms (RR 1.26; 95\% CI 1.13 to 1.42 ); dyspepsia (RR 1.28; 95\% CI 1.08 to 1.51); nausea (RR 1.24; 95\% CI 1.01 to 1.53 ); and abdominal pain (RR 1.24; 95\% CI 1.02 to 1.52$).^{76,80,86,87,89,90,94,96,97,99,100,104,106-108,122,123-126}$ The results for high-dose COX-2s were similar.

\section{Discussion}

The results of this systematic review demonstrate that there are several therapeutic strategies available to reduce the incidence of tNSAID related upper GI harms. Large, well powered, studies have shown that strategies using a tNSAID with misoprostol, or the use of a COX-2 instead of a tNSAID, each reduce the incidence of endoscopically detected upper GI ulcerations, and clinically important upper GI events such as bleeding. Misoprostol in doses that prevent upper GI ulcer complications is associated with important adverse effects which may limit its long-term use. Standard doses of H2RAs reduce the incidence of duodenal ulcers but are not effective at reducing the incidence of gastric ulcers. Double doses of H2RAs and standard-dose PPIs reduce the incidence of duodenal as well as gastric ulcers, but because tachyphylaxis can occur with chronic H2RA use, a standard-dose PPI

\begin{tabular}{|c|c|c|c|c|c|c|c|c|}
\hline Study or Subgroup & \multicolumn{2}{|c|}{ Treatment } & \multicolumn{2}{|c|}{ Control } & Weight & $\begin{array}{c}\text { Risk Ratio } \\
\text { M-H, Fixed, 95\% Cl }\end{array}$ & \multicolumn{2}{|c|}{$\begin{array}{c}\text { Risk Ratio } \\
\text { M-H, Fixed, 95\% CI }\end{array}$} \\
\hline MEDAL & 124 & 5680 & 112 & 11609 & $47.4 \%$ & $2.26[1.76,2.92]$ & & $\sqrt{-1}$ \\
\hline Schnitzer ${ }^{114}$ - TARGET & 45 & 2159 & 141 & 6968 & $42.9 \%$ & $1.03[0.74,1.44]$ & & \\
\hline Silverstein ${ }^{82}$ & 17 & 283 & 32 & 1101 & $8.4 \%$ & $2.07[1.16,3.67]$ & & \\
\hline Singh ${ }^{91}$ SUCCESS-I & 4 & 315 & 14 & 4079 & $1.3 \%$ & $3.70[1.23,11.17]$ & & \\
\hline Total $(95 \% \mathrm{Cl})$ & & 8437 & & 23757 & $100.0 \%$ & $1.74[1.44,2.09]$ & & \\
\hline Total events & 190 & & 299 & & & & & \\
\hline $\begin{array}{l}\text { Heterogeneity: } \text { Chi }^{2}=15 \\
\text { Test for overall effect: } \mathbf{Z}\end{array}$ & $\begin{array}{l}.85, \mathrm{df}= \\
=5.86(P\end{array}$ & $\begin{array}{l}3(P= \\
<0.00\end{array}$ & $\begin{array}{l}0.001) ; I^{2} \\
001)\end{array}$ & $=81 \%$ & & & 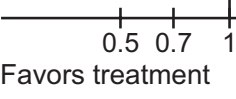 & $\begin{array}{l}1.52 \\
\text { Favors control }\end{array}$ \\
\hline
\end{tabular}

Figure 13 Clinical ulcers (PUBs [perforation, obstruction, bleeding or the presence of a symptomatic ulcer]) with tNSAID + ASA vs tNSAID alone. Note: This is a non-randomized comparison. 
strategy is preferred. H2RAs and PPIs have not been directly assessed in large primary prevention clinical outcome studies powered to detect ulcer complications. However, in secondary prevention studies of high-risk GI patients, tNSAIDs with a PPI appear as effective as a COX-2 strategy at preventing clinical ulcer complications. In these high-risk patients, these strategies were still associated with important ulcer relapse rates, suggesting that both strategies may provide incomplete protection for the secondary prevention of tNSAID-related ulcers. However, a recent study has shown that a strategy of combining a PPI with a COX-2 was superior to a COX-2 alone for the secondary prevention of ulcer complications, suggesting that a COX-2 + PPI strategy is the preferred strategy in high-risk GI patients. Further, the current metaanalysis, supported by the APPROVe polyp prevention study, ${ }^{9}$ has shown that while COX-2 offer greater GI safety than tNSAIDs as a group, COX-2 are associated with a statistically greater risk of clinical upper GI complications than those taking placebo.

The discovery that COX-2s are associated with important cardiovascular harm has complicated the clinical use of NSAIDs significantly. Further, in Canada, all COX-2 save celecoxib have been withdrawn from the market due to cardiovascular and other harms and it is unlikely that a new COX-2 would be released to market unless it is truly cardiovascularly neutral or it is combined with a GI-safe antithrombotic agent. During this time of uncertainty, when physicians were actively switching patients back to tNSAIDs + a gastropropective agent such as a PPI, it became increasingly clear that non-naproxen tNSAIDs were also associated with important CVS harms. ${ }^{11}$ A meta-analysis by Kearney et al using an extensive set of RCT data derived from published and unpublished studies has suggested that, as a group, COX-2s are associated with an increased risk of $\mathrm{CV}$ outcomes when compared with placebo or naproxen, but not when compared with non-naproxen, non-ASA tNSAIDs ${ }^{11}$ suggesting that non-naproxen-tNSAIDs share the cardiovascular harms of COX-2s.

In light of the cardiovascular harm data relating to COX-2s, it is tempting to suggest combining these agents with ASA. However, the available data from this metaanalysis suggest that this strategy would likely undermine the GI safety advantage of COX-2s. In patients taking ASA, we found no statistically significant difference in POBs or PUBs in patients randomized to a COX-2 or a tNSAID; however, the analyses did not stratify the randomization for ASA use. Thus, it is possible that other patient-related factors played a role in this result. Furthermore, although the analysis included about 7000 patients, it is still possible that a protective effect of COX-2s over tNSAIDs in this setting is present but not detected because of insufficient statistical power. We also found that the addition of ASA to a COX-2 significantly increased the risk of a POB 4.12-times over a COX-2 alone, and that the addition of ASA to a tNSAID demonstrated a nonsignificant 1.27 increased risk of POBs over the use of a tNSAID alone. One needs to note that these analyses represent nonrandomized comparisons, and that the group sizes were somewhat uneven (more patients in the COX-2 or tNSAID alone groups than in the groups with ASA). Nonetheless, the results are not entirely unexpected, because it has been known for some time that concomitant use of multiple NSAIDs increases the risk of GI complications over a single NSAID alone. These results are also in keeping with an RCT by Laine et $\mathrm{al}^{127}$ revealing that the incidence of endoscopically detected ulcers with rofecoxib and low-dose ASA was not lower than that seen with ibuprofen alone. However, it is clear that further study in this area is required to verify the above findings, such as through a dedicated RCT or from individual patient data systematic reviews. Further, adding ASA to a COX-2 implies that the COX-2s will not interfere with the effect of ASA. However, this hypothesis also requires further study because there are suggestions that the use of a tNSAID might interfere with the action of ASA in this setting, although there appears to be less interference with selective COX-2s. ${ }^{128-132}$

When COX-2s were released, they promised an era of improved GI safety, as well as an era of greater clinical simplicity, with the option of prescribing a single low risk agent when chronic NSAID use was required. However, with the greater understanding of the GI, cardiovascular, and other end organ safety profile of tNSAIDs and COX-2s, clinicians must now stratify their patients on the basis of GI, cardiovascular, and other organ system risk factors and choose an NSAID strategy, that minimizes a patient's overall risk. This has become especially difficult, for patients who are know to be at high risk of GI and cardiovascular harms.

When considering the treatment of an arthritic patient with a tNSAID or a COX-2, a clinician must consider the patient's underlying GI, cardiovascular, and other organ risks factors. Further, low-dose ASA is recommended for patients at increased cardiovascular risk; $;^{133,134}$ therefore an algorithm considering-high cardiovascular risk patients needs to assume the use of low-dose ASA in such patients. The recent Canadian Consensus Conference on NSAIDs proposed the following recommendations; ${ }^{135}$ For patients with both low GI and cardiovascular risk, a tNSAID alone may be acceptable. 
For patients with low GI risk and high cardiovascular risk, naproxen may be preferred because of the potential lower cardiovascular risk than with other tNSAIDs or COX-2s. However, since these patients are assumed to be on low-dose ASA therapy, the combination of naproxen plus ASA would increase the GI risk, and therefore, the addition of a gastroprotective agent such as a PPI should be considered.

Long-term NSAID therapy can be more complex in patients with high GI risk. Testing for and eradicating Helicobacter pylori in patients at high risk of NSAID-related GI bleeding should be considered but will be insufficient without ongoing gastroprotection..$^{57,136-139}$ In these patients, if cardiovascular risk is low, a COX-2 alone or a tNSAID with a PPI appear to offer similar protection from recurrent GI bleeding, but this protection is incomplete. Therefore, for patients at very high risk of upper GI events, a combination of a COX-2 plus a PPI may offer the best GI safety profile. When both GI and cardiovascular risks are high, the optimal strategy is to avoid NSAID therapy if at all possible. If the NSAID therapy is deemed necessary, then the clinician must prioritize the cardiovascular and GI risks, recognizing that these patients are likely taking ASA for their cardiovascular risk. If GI risk is the primary concern (ie, a very high-risk GI patient), a COX-2 plus a PPI is recommended. If the primary concern is cardiovascular risk, naproxen plus a PPI in patients on ASA would be preferred; however, GI risk should be closely monitored, as this strategy carries a higher GI risk than a COX-2 plus a PPI in patients on ASA. ${ }^{135}$

\section{Disclosures}

Dr. Rostom participated in an AstraZeneca advisory board in 2008. Dr. Lanas is or has been involved in advisory boards of studies sponsored by Pfizer, AstraZeneca and Bayer, and has also received funds for institutional research from Pfizer and AstraZeneca. In the past 5 years Dr. Tugwell has acted as a paid consultant for: AstraZeneca, Bristol-Myers Squibb, Chelsea, Eli Lilly, GlaxoSmithKline, Merck \& Co, Pennside, Pfizer, Scios, Solvay, UCB, and Wyeth Ayerst. The other authors report no conflicts of interest.

\section{References}

1. Barnard L, Lavoie D, Lajeunesse N. Increase in nonfatal digestive perforations and haemorrhages following introduction of selective NSAIDs: a public health concern. Drug Saf. 2006;29(7):613-620.

2. Roumie CL, Arbogast PG, Mitchel EF Jr, Griffin MR. Prescriptions for chronic high-dose cyclooxygenase-2 inhibitors are often inappropriate and potentially dangerous. J Gen Intern Med. 2005;20(10): 879-883.

3. Garcia RL, Jick H. Risk of upper gastrointestinal bleeding and perforation associated with individual non-steroidal anti-inflammatory drugs. Lancet. 1994;343(8900):769-772.
4. Derry S, Loke YK. Risk of gastrointestinal haemorrhage with long term use of aspirin: meta-analysis. BMJ. 2000;321(7270):1183-1187.

5. Rostom A, Wells G, Tugwell P, Welch V, Dube C, McGowan J. The prevention of chronic NSAID induced upper gastrointestinal toxicity: a Cochrane collaboration metaanalysis of randomized controlled trials. J Rheumatol. 2000;27(9):2203-2214.

6. Rostom A, Dubé C, Jolicoeur E, Boucher M, Joyce J. Gastroduodenal ulcers associated with the use of non-steroidal anti-inflammatory drugs: a systematic review of preventive pharmacological interventions. Technology report no 37. 2003. Ottawa, Canadian Coordinating Office for Health Technology Assessment.

7. Rostom A, Moayyedi P, Hunt R. Systematic Review: Canadian Consensus guidelines on long-term NSAID therapy and the need for gastroprotection. Aliment Pharmacol Ther. 2009;29(5): 481-496.

8. Lanas A, Baron JA, Sandler RS, et al. Peptic ulcer and bleeding events associated with rofecoxib in a 3-year colorectal adenoma chemoprevention trial. Gastroenterology. 2007;132(2):490-497.

9. Baron JA, Sandler RS, Bresalier RS, et al. A randomized trial of rofecoxib for the chemoprevention of colorectal adenomas. Gastroenterology. 2006;131(6):1674-1682.

10. Rostom A, Muir K, Dube C, et al. Gastrointestinal safety of cyclooxygenase-2 inhibitors: a Cochrane Collaboration systematic review. Clin Gastroenterol Hepatol. 2007;5(7):818-828.

11. Kearney PM, Baigent C, Godwin J, Halls H, Emberson J, Patrono C. Do selective cyclo-oxygenase-2 inhibitors and traditional nonsteroidal anti-inflammatory drugs increase the risk of atherothrombosis? Meta-analysis of randomised trials. BMJ. 2006;332: $1302-1308$.

12. McGettigan P, Henry D. Cardiovascular risk and inhibition of cyclooxygenase: a systematic review of the observational studies of selective and nonselective inhibitors of cyclooxygenase 2. JAMA. 2006;296(13):1633-1644.

13. Stupnicki T, Dietrich K, Gonzalez-Carro P, et al. Efficacy and tolerability of pantoprazole compared with misoprostol for the prevention of NSAID-related gastrointestinal lesions and symptoms in rheumatic patients. Digestion. 2003;68(4):198-208.

14. Melo GA, Roth SH, Zeeh J, Bruyn GA, Woods EM, Geis GS. Doubleblind comparison of efficacy and gastroduodenal safety of diclofenac/ misoprostol, piroxicam, and naproxen in the treatment of osteoarthritis. Ann Rheum Dis. 1993;52(12):881-885.

15. Watson DJ, Rahme E, Santanello NC. Increase in nonfatal digestive perforations and haemorrhages following introduction of selective NSAIDs: a public health concern. Drug Saf. 2007;30(1):89-90.

16. Higgins J, Green S. Cochrane Handbook for Systematic Reviews of Interventions Version 5.0.1. Higgins J, Green S, editors. The Cochrane Collaboration. 2008. The Cochrane Collaboration.

17. Rostom A, Wells G, Tugwell P, Welch V, Dube C, McGowan J. Prevention of NSAID-induced gastroduodenal ulcers. [update of Cochrane Database Syst Rev. 2000;(3):CD002296; 10908548.]. Cochrane Database Syst Rev. 2002; (4):CD002296.

18. Jadad AR, Moore RA, Carroll D, et al. Assessing the quality of reports of randomized clinical trials: is blinding necessary? Control Clin Trials. 1996;17(1):1-12.

19. Schulz K, Chalmers I, Hayes R, Altman D. Emperical evidence of bias: dimension of the methodological quality associated with estimates of treatment effects in controlled trials. JAMA. 1995;(273): 408-412.

20. Petitti D. Approaches to heterogeneity in meta-analysis. Stat Med. 2001;20(23):224-233.

21. Agrawal NM, Roth S, Graham DY, et al. Misoprostol compared with sucralfate in the prevention of nonsteroidal anti-inflammatory druginduced gastric ulcer. A randomized, controlled trial. Ann Intern Med. 1991;115(3):195-200.

22. Agrawal NM, Van KH, Erhardt LJ, Geis GS. Misoprostol coadministered with diclofenac for prevention of gastroduodenal ulcers. A one-year study. Dig Dis Sci. 1995;40(5):1125-1131. 
23. Bocanegra TS, Weaver AL, Tindall EA, et al. Diclofenac/misoprostol compared with diclofenac in the treatment of osteoarthritis of the knee or hip: a randomized, placebo controlled trial. Arthrotec Osteoarthritis Study Group. J Rheumatol. 1998;25(8):1602-1611.

24. Bolten W, Gomes JA, Stead H, Geis GS. The gastroduodenal safety and efficacy of the fixed combination of diclofenac and misoprostol in the treatment of osteoarthritis. Br J Rheumatol. 1992;31(11):753-758.

25. Chan FK, Sung JJ, Ching JY et al. Randomized trial of low-dose misoprostol and naproxen vs. nabumetone to prevent recurrent upper gastrointestinal haemorrhage in users of non-steroidal anti-inflammatory drugs. Aliment Pharmacol Ther. 2001;15(1):19-24.

26. Chandrasekaran AN, Sambandam PR, Lal HM, et al. Double blind, placebo controlled trial on the cytoprotective effect of misoprostol in subjects with rheumatoid arthritis, osteoarthritis and seronegative spondarthropathy on NSAIDs. J Assoc Physicians India. 1991; 39(12):919-921.

27. Cohen de Lara A, Gompel H, Baranes C, et al. Two comparative studies of dosmalfate vs misoprostol in the prevention of NSAID-induced gastric ulcers in rheumatic patients. Drugs Today. 2000;36 Suppl A:73-78.

28. Delmas PD, Lambert R, Capron MH. Misoprostol in the prevention of gastric erosions caused by nonsteroidal anti-inflammatory agents. Revue du Rhumatisme. 1994;Edition(2):126-131.

29. Elliott SL, Yeomans ND, Buchanan RR, Smallwood RA. Efficacy of 12 months' misoprostol as prophylaxis against NSAID-induced gastric ulcers. A placebo-controlled trial. Scand J Rheumatol. 1994;23(4): $171-176$.

30. Graham DY, Agrawal NM, Roth SH. Prevention of NSAID-induced gastric ulcer with misoprostol: multicentre, double-blind, placebocontrolled trial. Lancet. 1988;2(8623):1277-1280.

31. Graham DY, White RH, Moreland LW, et al. Duodenal and gastric ulcer prevention with misoprostol in arthritis patients taking NSAIDs. Misoprostol Study Group. Ann Intern Med. 1993;119(4):257-262.

32. Graham DY, Agrawal NM, Campbell DR, et al. Ulcer prevention in long-term users of nonsteroidal anti-inflammatory drugs: results of a double-blind, randomized, multicenter, active- and placebo-controlled study of misoprostol vs lansoprazole. Arch Intern Med. 2002;162(2): 169-175.

33. Hawkey CJ, Karrasch JA, Szczepanski L, et al. Omeprazole compared with misoprostol for ulcers associated with nonsteroidal antiinflammatory drugs. Omeprazole versus Misoprostol for NSAID-induced Ulcer Management (OMNIUM) Study Group. $N$ Engl $J$ Med. 1998;338(11):727-734.

34. Henriksson K, Uribe A, Sandstedt B, Nord CE. Helicobacter pylori infection, $\mathrm{ABO}$ blood group, and effect of misoprostol on gastroduodenal mucosa in NSAID-treated patients with rheumatoid arthritis. Dig Dis Sci. 1993;38(9):1688-1696.

35. Jensen DM, Ho S, Hamamah S, et al. A randomized study of omeprazole compared to misoprostol for prevention of recurrent ulcers and ulcer hemorrhage in high risk patients ingesting aspirin or NSAIDs [abstract]. Gastroenterology. 2000;118(4 Suppl 2 Pt 1):AGA A892.

36. Raskin JB, White RH, Jackson JE, et al. Misoprostol dosage in the prevention of nonsteroidal anti-inflammatory drug-induced gastric and duodenal ulcers: a comparison of three regimens. Ann Intern Med. 1995;123(5):344-350.

37. Raskin JB, White RH, Jaszewski R, Korsten MA, Schubert TT, Fort JG. Misoprostol and ranitidine in the prevention of NSAID-induced ulcers: a prospective, double-blind, multicenter study. Am J Gastroenterol. 1996;91(2):223-227.

38. Roth SH, Tindall EA, Jain AK, et al. A controlled study comparing the effects of nabumetone, ibuprofen, and ibuprofen plus misoprostol on the upper gastrointestinal tract mucosa. Arch Intern Med. 1993;153(22):2565-2571

39. Saggioro A, Alvisi V, Blasi A, Dobrilla G, Fioravanti A, Marcolongo R. Misoprostol prevents NSAID-induced gastroduodenal lesions in patients with osteoarthritis and rheumatoid arthritis. Ital $J$ Gastroenterol. 1991;23(3):119-123. Erratum in Ital J Gastroenterol. 1991;23(5):273.
40. Silverstein FE, Graham DY, Senior JR, et al. Misoprostol reduces serious gastrointestinal complications in patients with rheumatoid arthritis receiving nonsteroidal anti-inflammatory drugs. A randomized, double-blind, placebo-controlled trial. Ann Intern Med. 1995;123(4): 241-249.

41. Valentini M, Cannizzaro R, Poletti M, et al. Nonsteroidal antiinflammatory drugs for cancer pain: comparison between misoprostol and ranitidine in prevention of upper gastrointestinal damage. J Clin Oncol. 1995;13(10):2637-2642.

42. Verdickt W, Moran C, Hantzschel H, Fraga AM, Stead H, Geis GS. A double-blind comparison of the gastroduodenal safety and efficacy of diclofenac and a fixed dose combination of diclofenac and misoprostol in the treatment of rheumatoid arthritis. Scand J Rheumatol. 1992;21(2):85-91.

43. Berkowitz JM, Rogenes PR, Sharp JT, Warner CW. Ranitidine protects against gastroduodenal mucosal damage associated with chronic aspirin therapy. Arch Intern Med. 1987;147(12):2137-2139.

44. Ehsanullah RS, Page MC, Tildesley G, Wood JR. Prevention of gastroduodenal damage induced by non-steroidal anti-inflammatory drugs: controlled trial of ranitidine. BMJ. 1988;297(6655):1017-1021.

45. Robinson M, Mills RJ, Euler AR. Ranitidine prevents duodenal ulcers associated with non-steroidal anti-inflammatory drug therapy. Aliment Pharmacol Ther. 1991;5(2):143-150.

46. Robinson MG, Griffin JJ, Bowers J, et al. Effect of ranitidine on gastroduodenal mucosal damage induced by nonsteroidal antiinflammatory drugs. Dig Dis Sci. 1989;34(3):424-428.

47. Taha AS, Hudson N, Hawkey CJ, et al. Famotidine for the prevention of gastric and duodenal ulcers caused by nonsteroidal antiinflammatory drugs. $N$ Engl J Med. 1996;334(22):1435-1439.

48. Van Groenendael JH, Markusse HM, Dijkmans BA, Breedveld FC. The effect of ranitidine on NSAID related dyspeptic symptoms with and without peptic ulcer disease of patients with rheumatoid arthritis and osteoarthritis. Clin Rheumatol. 1996;15(5):450-456.

49. Levine LR, Cloud ML, Enas NH. Nizatidine prevents peptic ulceration in high-risk patients taking nonsteroidal anti-inflammatory drugs. Arch Intern Med. 1993;153(21):2449-2454.

50. Swift GL, Heneghan M, Williams GT, Williams BD, O'Sullivan MM, Rhodes J. Effect of ranitidine on gastroduodenal mucosal damage in patients on long-term non-steroidal anti-inflammatory drugs. Digestion. 1989;44(2):86-94.

51. Simon B, Muller P. Nizatidine in therapy and prevention of non-steroidal anti-inflammatory drug-induced gastroduodenal ulcer in rheumatic patients. Scand J Gastroenterol Suppl. 1994;206:25-28.

52. Hudson N, Taha AS, Russell RI, et al. Famotidine for healing and maintenance in nonsteroidal anti-inflammatory drug-associated gastroduodenal ulceration. Gastroenterology. 1997;112(6): $1817-1822$.

53. Wolde S, Dijkmans BA, Janssen M, Hermans J, Lamers CB. Highdose ranitidine for the prevention of recurrent peptic ulcer disease in rheumatoid arthritis patients taking NSAIDs. Aliment Pharmacol Ther. 1996;10(3):347-351.

54. Bianchi Porro G, Lazzaroni M, Imbesi V, Montrone F, Santagada T. Efficacy of pantoprazole in the prevention of peptic ulcers, induced by non-steroidal anti-inflammatory drugs: a prospective, placebocontrolled, double-blind, parallel-group study. Dig Liver Dis. 2000; 32(3):201-208.

55. Cullen D, Bardhan KD, Eisner M, et al. Primary gastroduodenal prophylaxis with omeprazole for non-steroidal anti-inflammatory drug users. Aliment Pharmacol Ther. 1998;12(2):135-140.

56. Ekstrom P, Carling L, Wetterhus S, et al. Prevention of peptic ulcer and dyspeptic symptoms with omeprazole in patients receiving continuous non-steroidal anti-inflammatory drug therapy. A Nordic multicentre study. Scand J Gastroenterol. 1996;31(8):753-758.

57. Lai KC, Lam SK, Chu KM, et al. Lansoprazole reduces ulcer relapse after eradication of Helicobacter pylori in nonsteroidal antiinflammatory drug users - a randomized trial. Aliment Pharmacol Ther. 2003;18(8):829-836. 
58. Yeomans ND, Tulassay Z, Juhasz L, Racz I, Howard J. A comparison of omeprazole with ranitidine for ulcers associated with nonsteroidal antiinflammatory drugs. N Eng J Med. 1998;338(11):719-726.

59. FDA - Study 21-Celebrex. Available from http://www.fda.gov/cder/ foi/adcomm/98/celebrex.htm). Accessed Aug 31, 2009.

60. FDA - Study 71-Celebrex. Available from http://www.fda.gov/cder/ foi/adcomm/98/celebrex.htm. Accessed Aug 31, 2009.

61. FDA - Study 47-FDA Review (ND21-341) - Bextra. Available from http://www.fda.gov/cder/foi/nda/2001/21-341_Bextra.htm. Accessed Aug 31, 2009.

62. FDA - Study 61-FDA Drug Review (ND21-341) - Bextra. Available from http://www.fda.gov/cder/foi/nda/2001/21-341_Bextra.htm. Accessed Aug 31, 2009.

63. FDA - Study 63-FDA Drug Review (ND21-341) - Bextra. Available from http://www.fda.gov/cder/foi/nda/2001/21-341_Bextra.htm) Accessed Aug 31, 2009.

64. Goldstein JL, Silverstein FE, Agrawal NM, et al. Reduced risk of upper gastrointestinal ulcer complications with celecoxib, a novel COX-2 inhibitor. Am J Gastroenterol. 2000;95(7):1681-1690.

65. Goldstein JL, Eisen GM, Agrawal N, Stenson WF, Kent JD, Verburg KM Reduced incidence of upper gastrointestinal ulcer complications with the COX-2 selective inhibitor, valdecoxib. Aliment Pharmacol Ther. 2004;20(5):527-538.

66. Langman MJ, Jensen DM, Watson DJ, et al. Adverse upper gastrointestinal effects of rofecoxib compared with NSAIDs. JAMA. 1999;282(20):1929-1933.

67. Distel M, Mueller C, Bluhmki E. Global analysis of gastrointestinal safety of a new NSAID, meloxicam. Inflammopharmacology. 1996;4(1):71-81.

68. Ramey DR, Watson DJ, Yu C, Bolognese JA, Curtis SP, Reicin AS. The incidence of upper gastrointestinal adverse events in clinical trials of etoricoxib vs non-selective NSAIDs: An updated combined analysis. Curr Med Res Opin. 2005;21(5):715-722.

69. Goldstein JL, Correa P, Zhao WW, et al. Reduced incidence of gastroduodenal ulcers with celecoxib, a novel cyclooxygenase-2 inhibitor, compared to naproxen in patients with arthritis. Am J Gastroenterol. 2001;96(4):1019-1027.

70. Emery P, Zeidler H, Kvien TK, et al. Celecoxib versus diclofenac in long-term management of rheumatoid arthritis: randomised doubleblind comparison. Lancet. 1999;354(9196):2106-2111.

71. Simon LS, Weaver AL, Graham DY, et al. Anti-inflammatory and upper gastrointestinal effects of celecoxib in rheumatoid arthritis: a randomized controlled trial.[see comment]. JAMA. 1999;282(20): 1921-1928.

72. Laine L, Harper S, Simon T, et al. A randomized trial comparing the effect of rofecoxib, a cyclooxygenase 2-specific inhibitor, with that of ibuprofen on the gastroduodenal mucosa of patients with osteoarthritis. Rofecoxib Osteoarthritis Endoscopy Study Group. Gastroenterology. 1999;117(4):776-783.

73. Hawkey C, Laine L, Simon T, et al. Comparison of the effect of rofecoxib (a cyclooxygenase 2 inhibitor), ibuprofen, and placebo on the gastroduodenal mucosa of patients with osteoarthritis: a randomized, double-blind, placebo-controlled trial. The Rofecoxib Osteoarthritis Endoscopy Multinational Study Group. Arthritis Rheum. 2000;43(2):370-377.

74. Hawkey CJ, Laine L, Simon T, et al. Incidence of gastroduodenal ulcers in patients with rheumatoid arthritis after 12 weeks of rofecoxib, naproxen, or placebo: a multicentre, randomised, double blind study. Gut. 2003;52(6):820-826. erratum in Gut. 2003;52(12):1800.

75. Hawkey CC, Svoboda P, Fiedorowicz-Fabrycy IF, et al. Gastroduodenal safety and tolerability of lumiracoxib compared with Ibuprofen and celecoxib in patients with osteoarthritis. J Rheumatol. 2004;31(9): 1804-1810.

76. Sikes DH, Agrawal NM, Zhao WW, Kent JD, Recker DP, Verburg KM. Incidence of gastroduodenal ulcers associated with valdecoxib compared with that of ibuprofen and diclofenac in patients with osteoarthritis. Eur J Gastroenterol Hepatol. 2002;14(10):1101-1111.
77. Pavelka K, Recker DP, Verburg KM. Valdecoxib is as effective as diclofenac in the management of rheumatoid arthritis with a lower incidence of gastroduodenal ulcers: results of a 26-week trial. Rheumatology. 2003;42(10):1207-1215.

78. Hunt RH, Harper S, Watson DJ, et al. The gastrointestinal safety of the COX-2 selective inhibitor etoricoxib assessed by both endoscopy and analysis of upper gastrointestinal events. Am J Gastroenterol. 2003;98(8):1725-1733.

79. Hunt RH, Harper S, Callegari P, et al. Complementary studies of the gastrointestinal safety of the cyclo-oxygenase-2-selective inhibitor etoricoxib. Aliment Pharmacol Ther. 2003;17(2):201-210.

80. Kivitz A, Eisen G, Zhao WW, Bevirt T, Recker DP. Randomized placebo-controlled trial comparing efficacy and safety of valdecoxib with naproxen in patients with osteoarthritis. J Fam Pract. 2002;51(6): 530-537.

81. Kivitz AJ, Nayiager S, Schimansky T, Gimona A, Thurston HJ, Hawkey C. Reduced incidence of gastroduodenal ulcers associated with lumiracoxib compared with ibuprofen in patients with rheumatoid arthritis. Aliment Pharmacol Ther. 2004;19(11):1189-1198.

82. Silverstein FE, Faich G, Goldstein JL, et al. Gastrointestinal toxicity with celecoxib vs nonsteroidal anti-inflammatory drugs for osteoarthritis and rheumatoid arthritis: the CLASS study: A randomized controlled trial. Celecoxib Long-term Arthritis Safety Study. JAMA. 2000;284(10):1247-1255

83. Bombardier C, Laine L, Reicin A, et al. Comparison of upper gastrointestinal toxicity of rofecoxib and naproxen in patients with rheumatoid arthritis. VIGOR Study Group. N Engl J Med. 2000;343(21): $1520-1528$

84. Dequeker J, Hawkey C, Kahan A, et al. Improvement in gastrointestinal tolerability of the selective cyclooxygenase (COX)-2 inhibitor, meloxicam, compared with piroxicam: results of the Safety and Efficacy Large-scale Evaluation of COX-inhibiting Therapies (SELECT) trial in osteoarthritis. Br J Rheumatol. 1998;37(9):946-951.

85. Hawkey C, Kahan A, Steinbruck K, et al. Gastrointestinal tolerability of meloxicam compared to diclofenac in osteoarthritis patients. International MELISSA Study Group. Meloxicam Large-scale International Study Safety Assessment. Br J Rheumatol. 1998;37(9):937-945. erratum in BrJ Rheumatol. 1998;37(10):1142.

86. Schnitzer TJ, Fricke J Jr, Gitton X, Jayawardene S, Sloan VS. Lumiracoxib in the treatment of osteoarthritis, rheumatoid arthritis and acute postoperative dental pain: Results of three dose-response studies. Curr Med Res Opin. 2005;21(1):151-161.

87. Leung AT, Malmstrom K, Gallacher AE, et al. Efficacy and tolerability profile of etoricoxib in patients with osteoarthritis: A randomized, double-blind, placebo and active-comparator controlled 12-week efficacy trial. Curr Med Res Opin. 2002;18(2):49-58.

88. Lisse JR, Perlman M, Johansson G, et al. Gastrointestinal tolerability and effectiveness of rofecoxib versus naproxen in the treatment of osteoarthritis: a randomized, controlled trial. Ann Intern Med. 2003;139(7):539-546.

89. Zhao SZ, McMillen JI, Markenson JA, et al. Evaluation of the functional status aspects of health-related quality of life of patients with osteoarthritis treated with celecoxib. Pharmacotherapy. 1999;19(11): 1269-1278.

90. Geusens PP, Truitt K, Sfikakis P, et al. A placebo and active comparator-controlled trial of rofecoxib for the treatment of rheumatoid arthritis. Scand J Rheumatol. 2002;31(4):230-238.

91. Singh G, Fort JG, Goldstein JL, et al. Celecoxib versus naproxen and diclofenac in osteoarthritis patients: SUCCESS-I Study. Am J Med. 2006;119(3):255-266.

92. Goldstein JL, Silverstein FE, Agrawal NM, et al. Reduced risk of upper gastrointestinal ulcer complications with celecoxib, a novel COX-2 inhibitor. Am J Gastroenterol. 2000;95(7):1681-1690.

93. Yocum D, Fleischmann R, Dalgin P, Caldwell J, Hall D, Roszko P. Safety and efficacy of meloxicam in the treatment of osteoarthritis: a 12-week, double-blind, multiple-dose, placebo-controlled trial. The Meloxicam Osteoarthritis Investigators. Arch Intern Med. 2000;160(19):2947-2954. 
94. Williams GW ERREHRLMYSZ. Treatment of osteoarthritis with a once-daily dosing regimen of celecoxib: A randomized, controlled trial. J Clin Rheumatol. 2000;6(2):65-74.

95. Bensen WG, Fiechtner JJ, McMillen JI, et al. Treatment of osteoarthritis with celecoxib, a cyclooxygenase-2 inhibitor: a randomized controlled trial. Mayo Clin Proc. 1999;74(11):1095-1105.

96. Truitt KE, Sperling RS, Ettinger WH Jr, et al. A multicenter, randomized, controlled trial to evaluate the safety profile, tolerability, and efficacy of rofecoxib in advanced elderly patients with osteoarthritis. Aging Clin Exp Res. 2001;13(2):112-121.

97. Day R, Morrison B, Luza A, et al. A randomized trial of the efficacy and tolerability of the COX-2 inhibitor rofecoxib vs ibuprofen in patients with osteoarthritis. Rofecoxib/Ibuprofen Comparator Study Group. Arch Intern Med. 2000;160(12):1781-1787.

98. Cannon GW, Caldwell JR, Holt P, et al. Rofecoxib, a specific inhibitor of cyclooxygenase 2 , with clinical efficacy comparable with that of diclofenac sodium: results of a one-year, randomized, clinical trial in patients with osteoarthritis of the knee and hip. Rofecoxib Phase III Protocol 035 Study Group. Arthritis Rheum. 2000;43(5): 978-987.

99. Ehrich EW, Schnitzer TM, Mcllwain H, et al. Effect of specific COX-2 inhibition in osteoarthritis of the knee: A 6 week double-blind, placebo controlled pilot study of rofecoxib. J Rheumatol. 1999; 26(11):2438-2447.

100. Schnitzer TJ, Truitt K, Fleischmann R. The safety profile, tolerability, and effective dose range of rofecoxib in the treatment of rheumatoid arthritis. Clin Ther. 1999;21(10):1688-1702.

101. Saag K, van der HD, Fisher C, et al. Rofecoxib, a new cyclooxygenase 2 inhibitor, shows sustained efficacy, comparable with other nonsteroidal anti-inflammatory drugs: a 6-week and a 1-year trial in patients with osteoarthritis. Osteoarthritis Studies Group. Arch Fam Med. 2000;9(10):1124-1134.

102. Geba GP, Weaver AL, Polis AB, Dixon ME, Schnitzer TJ, Vioxx ACTVG. Efficacy of rofecoxib, celecoxib, and acetaminophen in osteoarthritis of the knee: a randomized trial. JAMA. 2002;287(1): 64-71. erratum in JAMA. 200227;287(8):989.

103. Whelton A. Cyclooxygenase-2 - specific inhibitors and cardiorenal function: a randomized, controlled trial of celecoxib and rofecoxib in older hypertensive osteoarthritis patients. Am J Ther. 2001;8(2): 85-95.

104. McKenna F, Borenstein D, Wendt H, Wallemark C, Lefkowith JB, Geis GS. Celecoxib versus diclofenac in the management of osteoarthritis of the knee. Scand J Rheumatol. 2001;30(1): $11-18$.

105. McKenna F. COX-2 specific inhibitors in the management of osteoarthritis of the knee: A placebo-controlled, randomized, doubleblind study. J Clin Rheumatol. 2001;7(3):151-159.

106. Makarowski W, Zhao WW, Bevirt T, Recker DP. Efficacy and safety of the COX-2 specific inhibitor valdecoxib in the management of osteoarthritis of the hip: a randomized, double-blind, placebocontrolled comparison with naproxen. Osteoarthritis Cartilage. 2002;10(4):290-296.

107. Bensen W, Weaver A, Espinoza L, et al. Efficacy and safety of valdecoxib in treating the signs and symptoms of rheumatoid arthritis: a randomized, controlled comparison with placebo and naproxen. Rheumatology. 2002;41(9):1008-1016.

108. Gottesdiener K, Schnitzer T, Fisher C, et al. Results of a randomized, dose-ranging trial of etoricoxib in patients with osteoarthritis. Rheumatology (Oxford). 2002;41(9):1052-1061. Erratum in Rheumatology (Oxford). 2003;42(6):814.

109. Zacher J, Feldman D, Gerli R, et al. A comparison of the therapeutic efficacy and tolerability of etoricoxib and diclofenac in patients with osteoarthritis. Curr Med Res Opin. 2003;19(8):725-736. Erratum in Curr Med Res Opin. 2004;20(10):1689.

110. Collantes E, Curtis SP, Lee KW, et al. A multinational randomized, controlled, clinical trial of etoricoxib in the treatment of rheumatoid arthritis [ISRCTN25142273]. BMC Fam Pract. 2002;3(1):10.
111. Matsumoto AK, Melian A, Mandel DR, et al. A randomized, controlled, clinical trial of etoricoxib in the treatment of rheumatoid arthritis. J Rheumatol. 2002;29(8):1623-1630.

112. Kivitz AJ, Nayiager S, Schimansky T, Gimona A, Thurston HJ, Hawkey C. Reduced incidence of gastroduodenal ulcers associated with lumiracoxib compared with ibuprofen in patients with rheumatoid arthritis. Aliment Pharmacol Ther. 2004;19(11):1189-1198.

113. Hawkey CC, Svoboda P, Fiedorowicz-Fabrycy IF, et al. Gastroduodenal safety and tolerability of lumiracoxib compared with Ibuprofen and celecoxib in patients with osteoarthritis. $J$ Rheumatol. 2004;31(9): 1804-1810.

114. Schnitzer TJ, Burmester GR, Mysler E, et al. Comparison of lumiracoxib with naproxen and ibuprofen in the Therapeutic Arthritis Research and Gastrointestinal Event Trial (TARGET), reduction in ulcer complications: randomised controlled trial. Lancet. 2004;364(9435):665-674.

115. Goldstein JL, Agrawal N, Eisen G, et al. Significantly improved upper gastrointestinal (UGI) tolerability with celecoxib, a COX-2 specific inhibitor, compared with conventional NSAIDS. The Success-1 trial [abstract]. Abstracts in Perspective 5[1]. 2001.

116. Laine L, Curtis SP, Cryer B, Kaur A, Cannon CP. Assessment of upper gastrointestinal safety of etoricoxib and diclofenac in patients with osteoarthritis and rheumatoid arthritis in the Multinational Etoricoxib and Diclofenac Arthritis Long-term (MEDAL) programme: a randomised comparison. Lancet. 2007;369(9560): $465-473$.

117. U.S. Food and Drug Administration. Arthritis Drugs Advisory Committee Meeting 12/1/1998. CLASS - 12 Month Data. 1998. Available from.

118. Chan FK, Hung LC, Suen BY, et al. Celecoxib versus diclofenac plus omeprazole in high-risk arthritis patients: results of a randomized double-blind trial. Gastroenterology. 2004;127(4):1038-1043.

119. Lai KC, Chu KM, Hui WM, et al. Celecoxib compared with lansoprazole and naproxen to prevent gastrointestinal ulcer complications. Am J Med. 2005;118(11):1271-1278.

120. Chan FK, Wong VW, Suen BY, et al. Combination of a cyclooxygenase-2 inhibitor and a proton-pump inhibitor for prevention of recurrent ulcer bleeding in patients at very high risk: a double-blind, randomised trial. Lancet. 2007;369(9573):1621-6.

121. Myllykangas-Luosujarvi R, Lu HS, Chen SL, et al. Comparison of low-dose rofecoxib versus $1000 \mathrm{mg}$ naproxen in patients with osteoarthritis. Results of two randomized treatment trals of six weeks duration. Scand J Rheumatol. 2002;31(6):337-344.

122. Kivitz AJ, Moskowitz RW, Woods E, et al. Comparative efficacy and safety of celecoxib and naproxen in the treatment of osteoarthritis of the hip. J Int Med Res. 2001;29(6):467-479.

123. Wiesenhutter CW, Boice JA, Ko A, et al. Evaluation of the comparative efficacy of etoricoxib and ibuprofen for treatment of patients with osteoarthritis: A randomized, double-blind, placebo-controlled trial. Mayo Clin Proc. 2005;80(4):470-479.

124. Geusens P, Alten R, Rovensky J, et al. Efficacy, safety and tolerability of lumiracoxib in patients with rheumatoid arthritis. Int J Clin Pract. 2004;58(11):1033-1041.

125. Grifka JK, Zacher J, Brown JP, et al. Efficacy and tolerability of lumiracoxib versus placebo in patients with osteoarthritis of the hand. Clin Exp Rheumatol. 2004;22(5):589-596.

126. Lehmann R, Brzosko M, Kopsa P, et al. Efficacy and tolerability of lumiracoxib 100mg once daily in knee osteoarthritis: A 13-week, randomized, double-blind study vs. placebo and celecoxib. Curr Med Res Opin. 2005;21(4):517-526.

127. Laine L, Maller ES, Yu C, Quan H, Simon T. Ulcer formation with low-dose enteric-coated aspirin and the effect of COX-2 selective inhibition: a double-blind trial. Gastroenterology. 2004;127(2): 395-402.

128. Catella-Lawson F, Reilly MP, Kapoor SC, et al. Cyclooxygenase inhibitors and the antiplatelet effects of aspirin. $N$ Engl J Med. 2001;345(25):1809-1817. 
129. Ouellet M, Riendeau D, Percival MD. A high level of cyclooxygenase-2 inhibitor selectivity is associated with a reduced interference of platelet cyclooxygenase-1 inactivation by aspirin. Proc Natl Acad Sci U S A. 2001;98(25):14583-14588.

130. Baigent C, Patrono C. Selective cyclooxygenase 2 inhibitors, aspirin, and cardiovascular disease: a reappraisal. Arthritis Rheum. 2003;48(1):12-20.

131. Patrono C. Aspirin resistance: definition, mechanisms and clinical read-outs. J Thromb Haemost. 2003;1(8):1710-1713.

132. Cipollone F, Rocca B, Patrono C. Cyclooxygenase-2 expression and inhibition in atherothrombosis. Arterioscler Thromb Vasc Biol. 2004;24(2):246-255.

133. Khan NA, McAlister FA, Rabkin SW, et al. The 2006 Canadian Hypertension Education Program recommendations for the management of hypertension: Part II - Therapy. Can J Cardiol. 2006; 22(7):583-593.

134. Pearson TA, Blair SN, Daniels SR, et al. AHA Guidelines for Primary Prevention of Cardiovascular Disease and Stroke: 2002 Update: Consensus Panel Guide to Comprehensive Risk Reduction for Adult Patients Without Coronary or Other Atherosclerotic Vascular Diseases. American Heart Association Science Advisory and Coordinating Committee. Circulation. 2002;106(3):388-391.

135. Rostom A, Moayyedi P, Hunt R; for the Canadian Association of Gastroenterology Consensus group. Canadian consensus guidelines on long-term nonsteroidal anti-inflammatory drug therapy and the need for gastroprotection: benefits versus risks. Aliment Pharmacol Ther. 2009;29(5):481-496.
136. Chan FK, Chung SC, Suen BY, et al. Preventing recurrent upper gastrointestinal bleeding in patients with Helicobacter pylori infection who are taking low-dose aspirin or naproxen. $N$ Engl J Med. 2001;344(13):967-973.

137. Vergara M, Catalan M, Gisbert JP, Calvet X. Meta-analysis: role of Helicobacter pylori eradication in the prevention of peptic ulcer in NSAID users. Aliment Pharmacol Ther. 2005;21(12):1411-1418.

138. Labenz J, Blum AL, Bolten WW, et al. Primary prevention of diclofenac associated ulcers and dyspepsia by omeprazole or triple therapy in Helicobacter pylori positive patients: a randomised, double blind, placebo controlled, clinical trial. Gut. 2002;51(3):329-335.

139. Hunt R, Fallone C, Veldhuyzan van ZS, et al. Canadian Helicobacter Study Group Consensus Conference: Update on the management of Helicobacter pylori-an evidence-based evaluation of six topics relevant to clinical outcomes in patients evaluated for $\mathrm{H}$ pylori infection. Can J Gastroenterol. 2004;18(9):547-554.

140. Roth SH, Bennett RE, Mitchell CS, Hartman RJ. Cimetidine therapy in nonsteroidal anti-inflammatory drug gastropathy. Double-blind long-term evaluation. Arch Intern Med. 1987;147(10):1798-1801.

141. Tannenbaum H, Berenbaum F, Reginster JY, et al. Lumiracoxib is effective in the treatment of osteoarthritis of the knee: a 13 week, randomised, double blind study versus placebo and celecoxib. Ann Rheum Dis. 2004;63(11):1419-1426.

142. Williams G, Hubbard R, Yu SS Z. Comparison of once-daily and twicedaily administration of celecoxib for the treatment of osteoarthritis of the knee. Clin Ther. 2001;23(2):213-227.
Drug, Healthcare and Patient Safety

\section{Publish your work in this journal}

Drug, Healthcare and Patient Safety is an international, peer-reviewed open-access journal exploring patient safety issues in the healthcare continuum from diagnostic and screening interventions through to treatment, drug therapy and surgery. The journal is characterized by the rapid reporting of reviews, original research, clinical, epidemiological and

\section{Dovepress}

post-marketing surveillance studies, risk management, health literacy and educational programs across all areas of healthcare delivery. The manuscript management system is completely online and includes a very quick and fair peer-review system. Visit http://www.dovepress.com/ testimonials.php to read real quotes from published authors. 